\title{
A Theory of Merger-Driven IPOs
}

\author{
Jim Hsieh, Evgeny Lyandres, and Alexei Zhdanov*
}

\begin{abstract}
We propose a model that links a firm's decision to go public with its subsequent takeover strategy. A private bidder does not know a firm's true valuation, which affects its gain from a potential takeover. Consequently, a private bidder pursues a suboptimal restructuring policy. An alternative route is to complete an initial public offering (IPO) first. An IPO reduces valuation uncertainty, leading to a more efficient acquisition strategy, therefore enhancing firm value. We calibrate the model using data on IPOs and mergers and acquisitions (M\&As). The resulting comparative statics generate several novel qualitative and quantitative predictions, which complement the predictions of other theories linking IPOs and M\&As. For example, the time it takes a newly public firm to attempt an acquisition of another firm is expected to increase in the degree of valuation uncertainty prior to the firm's IPO and in the cost of going public, and it is expected to decrease in the valuation surprise realized at the time of the IPO. We find strong empirical support for the model's predictions.
\end{abstract}

\section{Introduction}

Recent empirical studies suggest that firms' initial public offerings (IPOs) and mergers and acquisitions (M\&As) are not unrelated. According to a survey of

*Hsieh, jhsieh@gmu.edu, School of Management, George Mason University, 4400 University Dr., Fairfax, VA 22030; Lyandres, lyandres@bu.edu, School of Management, Boston University, 595 Commonwealth Ave., Boston, MA 02445; and Zhdanov, azhdanov@unil.ch, University of Lausanne, Extranef 237, Lausanne 1007, Switzerland and Swiss Finance Institute. We are grateful to Rui Albuquerque, Yakov Amihud, Simon Benninga, Gennaro Bernile, David Chapman, Thomas Chemmanur, Ilan Cooper, François Degeorge, Jerome Detemple, Darrell Duffie, Bernard Dumas, David Feldman, Amit Goyal, Gustavo Grullon, Natalia Guseva, Kathleen Hanley, Jarrad Harford, Jean Helwege, David Hirshleifer, Gerard Hoberg, Philippe Jorion, Dalida Kadyrzhanova, Avner Kalay, George Kanatas, Ambrus Kecskés, Darren Kisgen, Yrjo Koskinen, Pete Kyle, Vojislav Maksimovic, Paul Malatesta (the editor), Alan Marcus, Marc Martos-Villa, Pierre Mella-Barral, Antonio Mello, Brad Paye, Gordon Phillips, Lukasz Pomorski, Nagpurnanand Prabhala, Michael Salinger, Norman Schürhoff, Matthew Spiegel, Hassan Tehranian, Kerry Vandell, James Weston, and seminar participants at Ben Gurion University, Boston College, Boston University, George Mason University, Norwegian School of Economics and Business Administration, University of California at Irvine, University of Lausanne, University of Maryland, Rice University, Tel Aviv University, 2008 Western Finance Association Meetings, 2008 National Centre of Competence in Research (NCCR)-Financial Valuation and Risk Management (FINRISK) Summer Workshop at Gerzensee, and 2008 European Finance Association Meetings for helpful comments. We are especially grateful to Erwan Morellec (the referee) for excellent suggestions that improved the paper considerably. All remaining errors are ours only. 
336 CFOs by Brau and Fawcett (2006), facilitating potential takeover transactions is one of the most important motivations for going public. Schultz and Zaman (2001) find evidence that many Internet firms that went public in the late 1990s pursued aggressive post-IPO acquisition strategies. Celikyurt, Sevilir, and Shivdasani (2010) report that newly public firms grow predominantly through M\&As in the first 5 post-IPO years. Similarly, Hovakimian and Hutton (2010) report that over $1 / 3$ of newly public firms enter the market for corporate control as acquirers within 3 years of the IPO. Rau and Stouraitis (2011) find that IPO waves are followed by stock-financed merger waves. Maksimovic, Phillips, and Yang (2010) document that public firms engage in mergers more than private firms.

There are two existing theories that suggest that IPOs may facilitate future acquisitions. First, a private bidder contemplating a stock merger may decide to go public to alleviate the asymmetric information problem (e.g., Hansen (1987), Fishman (1989), and Eckbo, Giammarino and Heinkel (1990)). These information-asymmetry-based theories provide an explanation for the link between IPOs and stock acquisitions, but they do not explain post-IPO cash acquisitions, which constituted over $1 / 4$ of acquisitions in the last 30 years, while the acquisition currency of another $20 \%$ of M\&As was a mixture of cash and stock. Second, an IPO could be a means to obtain cash to be used in future acquisitions (e.g., Mikkelson, Partch, and Shah (1997)). However, there are many IPOs in which very little external capital is raised. For example, 100 IPOs between 1985 and 2006 involved only a secondary component (i.e., no external funds were raised during these IPOs), including IPOs by well-known companies such as Lucent Technologies and Morningstar, and IPOs of many more firms involved a relatively small primary component. Many such firms have acquired other companies shortly after their IPOs. ${ }^{1}$ The cash infusion theory cannot explain the link between IPOs and subsequent cash mergers by firms that raised no or little external funds during their IPOs.

An interesting feature of many IPOs that are later followed by acquisitions of other companies is that a newly public firm is more likely to acquire other firms if it realizes a positive "valuation surprise" around its IPO (i.e., if the firm's realized post-IPO valuation is substantially higher than its expected post-IPO value). On the other hand, firms that realize negative valuation surprises around their IPOs are less likely to pursue acquisitions in the future. This observation is potentially consistent with an alternative theory linking IPOs and subsequent M\&As that we propose in this paper, which complements the information-asymmetry-based and cash-infusion-based theories of IPOs facilitating future acquisitions.

Absent market valuation, there is uncertainty surrounding the value of a private firm's capital, which affects the gain from a potential takeover if the firm chooses to merge with another firm in the future. A private firm, not knowing the precise value of its capital, is unable to make optimal takeover decisions. Thus, valuation uncertainty leads to suboptimal M\&A policy and reduces firm value. An IPO reduces valuation uncertainty and allows the firm to pursue a more

\footnotetext{
${ }^{1}$ Lucent Technologies acquired Octel Communications for $\$ 1.8$ billion in cash 15 months after Lucent's IPO, while Morningstar bought Ibbotson Associates for $\$ 83$ million in cash 7 months after Morningstar's IPO.
} 
efficient acquisition strategy or, in other words, to exercise its restructuring option optimally. Importantly, while firms raising no external funds during their IPOs serve as a good illustration of the valuation-uncertainty-based theory of mergerdriven IPOs, our theory can be applied to a much broader set of firms considering going public in anticipation of future acquisitions, since our model complements the existing theories linking IPOs and M\&As along a number of important dimensions.

First, the timing dimension is very important in our model. The optimal exercise of the option to go public and the option to merge leads to novel predictions about the time that elapses between an IPO and a subsequent merger and about the probability of observing an acquisition by a newly public firm in the years following its IPO. Thus, in addition to providing a novel link between IPOs and mergers, our model generates a number of unique empirical predictions that relate the likelihood and timing of post-IPO M\&As to various firm and industry characteristics, such as the degree of valuation uncertainty surrounding a firm, the cost of going public, and the valuation surprise realized at the time of an IPO.

Second, we assume rational investors and efficient markets in which securities are fairly priced. On the contrary, existing models assume that managers have private information about firms going public (e.g., Chemmanur and Fulghieri (1999), Maksimovic and Pichler (2001)). Although some information about firms going public is surely asymmetric, it is useful to know which empirical regularities about IPOs can be explained in a more parsimonious world of symmetric information. Our model shows that reduction in valuation uncertainty can get us far in understanding the link between IPO and M\&A activity even in the absence of information asymmetry. In other words, asymmetric information is important, but the mechanism in our paper plays its own distinct role in linking IPOs and M\&As. Our theory should hold for all acquisitions, regardless of the method of payment, in contrast to the asymmetric information theory (which predicts disproportionately many stock mergers following IPOs) and the cash infusion story (predicting disproportionately many cash acquisitions).

In addition to reducing uncertainty about firm value, performing an IPO allows a potential bidder to credibly communicate its valuation to a potential target. Importantly, while we focus our discussion and the model on the benefit of an IPO to potential bidders, firms that consider themselves potential acquisition targets have a similar motivation to go public. Our theory can be applied to the case of potential target firms.

The basic assumption behind our analysis, that firms learn their valuation from the capital market, appears reasonable. The effect of an IPO on the reduction in a firm's valuation uncertainty has been highlighted in several models. For example, Benveniste and Spindt (1989) model the process through which investors reveal their information about an IPO firm to its underwriter. In Dow and Gorton (1997), stock market traders have information about firms' investment opportunities that managers do not have. Alt1 (2005) shows that IPOs result in a release of investors' private information and cause information spillovers to other firms considering going public, which, in turn, facilitates their IPOs. Similarly, Benveniste, Busaba, and Wilhelm (2002) suggest that IPO firms generate information externalities for other firms in their industry. In Chemmanur and 
Fulghieri's (1999) model, a firm trades off information production costs in the IPO market versus the risk premium required by private financiers. Derrien and Kecskés (2007) argue that the main reason for U.K. firms to list their shares without issuing new equity is the resulting reduction in valuation uncertainty, which leads to lowering the costs of subsequent equity offerings.

The assumption that firms' managers adjust the valuations of their firms following updates in market valuations is also supported by existing empirical evidence. For example, Brau and Fawcett (2006) document that 51\% of surveyed CFOs regard the impact of post-IPO stock price on their assessment of the company's value as important. Luo (2005) finds that the market reaction to an M\&A announcement predicts the likelihood of the consummation of the proposed deal, suggesting that "insiders learn from outsiders." Subrahmanyam and Titman (2001) argue that one of the reasons for the importance of market valuation is that it impacts firms' cash flows through its effect on the actions of firms' nonfinancial stakeholders.

The logic of our model is consistent with the fact that private firms that require access to public equity markets can choose between an IPO and an acquisition of a public firm or by a public firm (e.g., Brau, Francis, and Kohers (2003)). In our model, some private firms go public through a traditional IPO, while others become public by merging directly with seasoned public firms. The sequential link between IPOs and M\&As that we propose suggests that the merger/IPO decisions are not mutually exclusive but can, instead, be complementary.

To examine the economic importance of our theory, we calibrate the model using M\&A and IPO data from the Securities Data Company (SDC) and analyze the quantitative (economic) effects of various parameters of the model on the likelihood of mergers following IPOs. We find that many of the parameters, especially the degree of valuation uncertainty and valuation surprise revealed at the time of an IPO, have economically important effects on the likelihood and timing of acquisitions by newly public firms. This timing dimension is generally missing in alternative theories, whose literal interpretation leads to mergers immediately following IPOs.

We also perform empirical tests of our model's predictions. The empirical evidence provides support for the predictions regarding the likelihood and timing of post-IPO mergers. The time it takes a newly public firm to attempt an acquisition of another firm is increasing in the degree of valuation uncertainty prior to the firm's IPO and in the cost of going public, and it is decreasing in the valuation surprise realized at the time of the IPO.

To summarize, our paper contributes to the IPO literature by suggesting a new motivation for going public. In addition to raising external capital, IPOs may be driven by product market competition (e.g., Maksimovic and Pichler (2001), Stoughton, Wong, and Zechner (2001)), market timing (e.g., Alt1 (2005)), liquidity (e.g., Amihud and Mendelson (1988)), dispersed ownership (e.g., Zingales (1995), Mello and Parsons (1998)), executive remuneration contracts (e.g., Holmström and Tirole (1993)), and diversification (e.g., Benninga, Helmantel, and Sarig (2005)). We argue that an additional important reason for a firm to go public is the resulting ability to optimally exercise its restructuring option. 
Our analysis is also related to several articles that examine M\&As in a dynamic framework (e.g., Lambrecht (2004), Lambrecht and Myers (2007), Leland (2007), Hackbarth and Miao (2007), Bernile, Lyandres, and Zhdanov (2011), Hackbarth and Morellec (2008), Margsiri, Mello, and Ruckes (2008), and Morellec and Zhdanov (2008)). We introduce a new theme into this literature by linking IPO and M\&A markets. Private firms seeking takeover opportunities exercise their options to merge with other firms either through 1-step (without an IPO) or 2-step (with an IPO) acquisitions.

The remainder of the paper is organized as follows. The next section presents the model linking the IPO and restructuring decisions. In Section III we calibrate the model using real-world data on mergers and IPOs and perform a comparative statics analysis of the likelihood of M\&As following IPOs, which generates qualitative and quantitative empirical predictions. Section IV presents empirical tests of the model's predictions. We summarize our theoretical results and empirical findings and conclude in Section V. Proofs are provided in the Appendix.

\section{Model}

In this section we present a model that demonstrates the potential benefit of going public before engaging in M\&As. The benefit of an IPO is that a publicly traded firm is able to evaluate the takeover gain resulting from a potential acquisition more precisely than a similar private firm. The ability to reduce the uncertainty regarding the future takeover surplus allows a public firm to exercise its option to merge optimally, whereas a private firm has to base the restructuring (merging) decision on incomplete information about the potential takeover gain. The trade-off between the benefit of going public and the direct cost of doing so provides interesting predictions regarding the driving forces behind the IPO decision, its optimal timing, and the timing of subsequent acquisitions.

In the model we focus on the case in which a private bidder contemplates a merger with a potential public target and may decide to go public in order to be able to exercise its restructuring option optimally. Note, however, that our model is fully adaptable to the opposite case, in which a privately held target goes through an IPO to increase the value of its option to be acquired, and almost identical results are obtained. ${ }^{2}$

The dynamic nature of our real options model is essential for our analysis. The values of the option to go public and the option to engage in a merger depend on when these options are exercised. The optimal timing of their exercise is endogenously determined in the model, which generates numerous predictions regarding the expected time between IPOs and subsequent takeovers. Such predictions could not be obtained in a static model. Furthermore, our model

\footnotetext{
${ }^{2}$ It can be shown that our model also holds for the case in which a firm's role as a potential bidder or target is not predetermined at the time of IPO and depends on the post-IPO evolution of firm values. The model can also be extended to the case of a private bidder considering an acquisition of a private target and to the case in which a firm going public can choose whether to become a bidder or target. These extensions, as well as other unincluded extensions we mention later, are available from the authors.
} 
allows quantifying the effects of firm and industry characteristics on probabilities of observing post-IPO takeovers and their timing. ${ }^{3}$

\section{A. Assumptions and Discussion}

\section{Assumption 1. The Bidder's and Target's Capital Stocks and Valuation}

We follow Morellec and Zhdanov (2005) and Hackbarth and Morellec (2008) and assume that there exist 2 firms: a potential bidder and a potential target with per-unit-of-capital valuations of their core businesses denoted by $X(t)$ and $Y(t)$, respectively, at time $t .{ }^{4}$ The bidder's and target's capital stocks are denoted by $K_{B}$ and $K_{T}$, respectively.

Initially, the potential acquirer is a privately held company. Absent a value attributed by market investors, the bidder has only a noisy signal about its true value. Therefore, $X$ is the private bidder's management's subjective estimate of its value. The true per-unit value of the bidder's capital is $X_{\mathrm{TRUE}}=X(1+\varepsilon)$. The valuation error, $\varepsilon$, is not observed by management, since, as argued in the Introduction, dispersed investors may have information about the value of the firm's capital that the management does not have. Thus, management's valuation is almost always either strictly below $(\varepsilon>0)$ or strictly above $(\varepsilon<0)$ the true value. We further assume that management's valuation is unbiased, $\mathbb{E}(\varepsilon)=0(X=$ $\left.\mathbb{E}\left(X_{\mathrm{TRUE}}\right)\right)$, and that $\varepsilon$ is drawn from a uniform distribution with support $[-\lambda, \lambda]$, where $\lambda>0 . .^{5}$ The distribution of the valuation error is assumed to be known to management. Since the target is public, its true per-unit-of-capital stock market valuation, $Y_{\mathrm{TRUE}}$, is known. As mentioned previously, the model can be adjusted to the case of a private target whose subjective valuation, $Y$, is unbiased: $Y=$ $\mathbb{E}\left(Y_{\text {TRUE }}\right)$. In what follows, we slightly abuse the notation and write $Y$ instead of $Y_{\text {TRUE }}$.

Note that our assumptions do not imply that there is misvaluation or that financial markets are inefficient. As long as the bidder is private, its market valuation is not observable. This precludes the bidder's management from knowing the precise value of the firm. We also assume that the target's management has the same beliefs about the value of the bidder as the bidder's management, so there is no information asymmetry between the bidder and the target, but the valuation of the bidder's capital is noisy. As becomes clear later, the imperfect information

\footnotetext{
${ }^{3}$ In addition, real options in our model (as in most real options models) are optimally exercised when they are strictly in the money. This differentiates our model from a static setup, in which the decisions to merge and to go public would have to be based on the simple net present value rule. This difference is essential. In unincluded analysis, we show that allowing for reversibility of a merger bid in cases in which the revealed takeover gain is negative, produces an immaterial effect on our results. This happens because the option to go public is only exercised when the (expected) value of the restructuring option is strictly positive. On the contrary, introducing merger bid reversibility in a static model would make the option to go public worthless.

${ }^{4}$ In unincluded analysis, we extend the model to the case of competition for a target between 2 bidders. While the quantitative effects of going public on the value of the restructuring option are reduced in the presence of competition, the model's qualitative (directional) results remain intact.

${ }^{5}$ The assumption of a particular distribution of valuation errors does not drive any of the results as long as management's estimate of the firm's value is unbiased.
} 
about the bidder's value affects the value of its option to merge with the potential target.

The bidder management's subjective valuation and the target's valuation are governed by the following stochastic processes:

$$
d A(t)=\mu_{A} A(t) d t+\sigma_{A} A(t) d W_{A}(t), \quad A=\{X, Y\}
$$

where $\mu_{X}<r, \mu_{Y}<r, \sigma_{X}>0$, and $\sigma_{Y}>0$ are constant parameters and $W_{X}$ and $W_{Y}$ are standard Brownian motions on $(\Omega, \mathcal{F}, P)$. In addition, we assume that the correlation coefficient between the two sources of uncertainty, $W_{X}$ and $W_{Y}$, is constant and equals $\rho$.

\section{Assumption 2. IPO and Valuation Uncertainty}

We assume that the (initially privately held) bidder has an option to become public by going through an IPO. If the bidder goes public, the market's (true) per-unit valuation, $X_{\mathrm{TRUE}}$, is revealed to both the bidder and the potential target and is assigned to the bidder's stock of capital. Thus, an IPO eliminates uncertainty regarding the bidder's value. It is worth noting that, while our assumption that all uncertainty about the bidder's value is eliminated following the IPO may be deemed extreme, it is made for the sake of simplicity. Identical qualitative results are obtained under the assumption that the valuation uncertainty is only partially reduced as a result of the IPO.

In our setting, a reduction in the bidder's valuation uncertainty potentially increases its value because it allows the bidder to choose the timing of its future acquisitions optimally. While it is possible to eliminate valuation uncertainty in ways other than going through an IPO (i.e., by merging "blindly" with a public target and using it as a "shell" (e.g., Brau et al. (2003)), such mechanism of going public would not lead to optimal acquisition timing. Thus, in our model, which is applicable to private firms seeking to grow via takeovers, an IPO is the only method of reducing valuation uncertainty in a way that can contribute to firm value.

\section{Assumption 3. Takeover Gain and Cost}

At any time $t>0$, the bidder and target can negotiate a takeover deal. We follow Morellec and Zhdanov (2005) and Hackbarth and Morellec (2008) by assuming that the combined firm's posttakeover value is a linear combination of the bidder's and target's pretakeover true values of capital. In addition, we follow Lambrecht (2004) and assume that each party incurs a fixed direct cost of going through a merger. This cost is assumed proportional to the value of each firm's capital. In particular, the posttakeover value of the combined firm is given by

$$
\begin{aligned}
V\left(X_{\mathrm{TRUE}}, Y\right)= & K_{B} X_{\mathrm{TRUE}}+K_{T} Y+\alpha K_{T}\left(X_{\mathrm{TRUE}}-Y\right) \\
& -c\left(K_{B} X_{\mathrm{TRUE}}+K_{T} Y\right),
\end{aligned}
$$

where $\alpha$ is the "takeover gain factor" and $c>0$ is the "cost factor." A merger can occur only if the takeover gain exceeds its cost for some levels of $X_{\mathrm{TRUE}}$ and $Y$. (A necessary condition for the possibility of takeover is $\alpha K_{T}-c K_{B}>0$; this expression is the increase in the net takeover gain caused by a marginal increase in the 
value of the bidder's capital, $X_{\mathrm{TRUE}}$.) Since the target is public and the combined postmerger firm is public regardless of the bidder's premerger status, it is natural to assume that the takeover gain is a function of the true value of the bidder (as opposed to the bidder management's subjective valuation if it is private).

At the time of the merger, the combined bidder's and target's takeover gain, $G^{C}\left(X_{\mathrm{TRUE}}, Y\right)$, equals the combined takeover surplus net of merger cost:

$$
G^{C}\left(X_{\mathrm{TRUE}}, Y\right)=\alpha K_{T}\left(X_{\mathrm{TRUE}}-Y\right)-c\left(K_{B} X_{\mathrm{TRUE}}+K_{T} Y\right) .
$$

Note that the takeover gain in equation (3) is the "true" net takeover surplus, which is not equal to the change in the value of the combined firm relative to the sum of the pretakeover target's value and private bidder management's subjective valuation. The reason is that at the time of the takeover, the private bidder management's valuation error, $\varepsilon$, and the true per-unit-of-capital bidder's value, $X_{\text {TRUE }}$, are revealed. Thus, a takeover by a private bidder of a public target results in a gain or loss equaling $K_{B} X \varepsilon$ in addition to the realized takeover surplus. However, this gain/loss is a random variable with 0 mean from the private bidder's perspective and, as will be shown later, it does not affect the restructuring decision.

Importantly, the setup of the model limits us to an analysis of a merger between firms with physical capital, in which the synergies follow from the superior ability of a bidder to utilize a target's capital. Our model is silent about the motivations for and the outcomes of takeovers by private raiders, leveraged buyouts (LBOs), and management buyouts (MBOs), in which a bidder only provides its management's expertise in managing the target's capital, while not contributing capital of its own.

Equation (3) shows that the takeover surplus can be positive only when the acquiring firm has a higher valuation of its capital than the target $\left(X_{\mathrm{TRUE}}>Y\right)$. If this is the case, restructuring results in a more efficient allocation of resources. This specification is consistent with the Q-theory of mergers (e.g., Jovanovic and Rousseau (2002), Lambrecht (2004)) that treats takeover targets as the bidders' source of capital. According to the Q-theory, mergers are a tool to efficiently allocate capital to the most productive users. Similarly, in Maksimovic and Phillips' (2002) model, less productive firms sell their capacity to more productive ones. Maksimovic and Phillips (2001) provide plant-level empirical evidence consistent with efficient reallocation of resources in mergers and conclude that "the gain in productivity of assets under new ownership is higher when the selling firm's productivity is low and is higher the more productive the buyer." Thus, it is natural to assume that the takeover gain is larger the larger the contribution of a more efficient bidder to the value of the target's capital.

\section{Assumption 4. IPO Cost}

Going public is not free. The underwriting fees make an IPO a costly undertaking. We assume that if the potential bidder decides to go public, a cost proportional to the true value of its capital, $\eta K_{B} X_{\mathrm{TRUE}}$, must be incurred, where $\eta>0$. 


\section{Assumption 5. Discounting}

All parties are risk neutral; the risk-free discount rate is $r$.

\section{B. Solution}

The timing of a potential takeover depends on the combined net takeover surplus as well as its allocation between the bidder and target. Also, as discussed later, the restructuring policy depends on whether the bidder's true value, $X_{\mathrm{TRUE}}$, is known (i.e., whether the bidder has become public prior to launching a takeover bid or has decided to stay private). The difference between the optimal takeover strategies of a private bidder and a public one drives the decision to go public and its timing, and it is at the core of our model.

We begin the analysis by finding the takeover timing that maximizes the value of the restructuring option. We perform this analysis first for the case of a public bidder and then proceed to the private bidder case. We then consider the optimal IPO timing of a potential bidder that is initially private. The decision to go public involves the trade-off between the benefit of being able to exercise the restructuring option optimally and the IPO cost.

Our solution technique relies on finding the fractions of the takeover surplus that accrue to the bidder's and target's shareholders, so that the 2 firms would have identical optimal restructuring policies. (The 2 firms would be willing to exercise the merger option at exactly the same time.) Suppose that the takeover agreement specifies that a fraction $\xi$ of the combined takeover surplus accrues to the bidder's shareholders upon takeover consummation ( $\xi$ is determined endogenously later). Such an agreement implies that the net gain that the bidding firm's shareholders extract from the merger, $G^{B}\left(X_{\mathrm{TRUE}}, Y\right)$, is

$$
G^{B}\left(X_{\mathrm{TRUE}}, Y\right)=\xi \alpha K_{T}\left(X_{\mathrm{TRUE}}-Y\right)-c K_{B} X_{\mathrm{TRUE}},
$$

whereas the surplus accruing to the target's shareholders, $G^{T}\left(X_{\mathrm{TRUE}}, Y\right)$, is given by

$$
G^{T}\left(X_{\mathrm{TRUE}}, Y\right)=(1-\xi) \alpha K_{T}\left(X_{\mathrm{TRUE}}-Y\right)-c K_{T} Y
$$

The 1 st term in equation (4) is the share of the bidder's shareholders in combined takeover surplus. The 2 nd term is the bidder's cost of merging. Similar interpretation applies to the target's shareholders' net gain in equation (5). ${ }^{6}$

Because the private bidder's valuation surprise is a random variable with 0 mean, regardless of whether the bidder has gone public or remained private, its optimal restructuring policy is determined by maximizing the value of its option to merge. The value of that option and its optimal exercise strategy depend on

\footnotetext{
${ }^{6}$ The method of payment is immaterial in our model because there is no information asymmetry between the bidder and target. If the takeover currency is the bidder's stock, then, if the bidder is public, the target's shareholders would receive a fraction $\left(K_{T} Y+(1-\xi) \alpha K_{T}\left(X_{\mathrm{TRUE}}-Y\right)\right) /$ $\left(K_{B} X_{\mathrm{TRUE}}+K_{T} Y+\alpha K_{T}\left(X_{\mathrm{TRUE}}-Y\right)\right)$ of the merged firm's stock, while if the method of payment is cash, then the target's shareholders would receive $K_{T} Y+(1-\xi) \alpha K_{T}\left(X_{\mathrm{TRUE}}-Y\right)$ in cash for their shares. Similar expressions, with $X_{\mathrm{TRUE}}$ substituted by $X$, describe the payment to the target's shareholders in the case of a private bidder.
} 
the bidder's true valuation, $X_{\mathrm{TRUE}}$. While a public bidder, with known $X_{\mathrm{TRUE}}$, can optimize its merger timing depending on its value, a private bidder, which treats $X_{\text {TRUE }}$ as a random variable with known distribution, can only select its restructuring policy by maximizing the expected value of the option to merge (where the expectation is formed over the distribution of the valuation surprise, $\varepsilon$ ).

\section{Acquisition by Public Bidder}

The value of the option to merge depends on the true values of the bidder's and target's capital, $X_{\mathrm{TRUE}}$ and $Y$, respectively. Since the values of total net takeover gain in equation (3) and the bidder's and target's shares of the surplus net of their cost of merging, in equations (4) and (5), respectively, are linearly homogenous in $X_{\mathrm{TRUE}}$ and $Y$, the value of the restructuring option depends on the relative values of the bidder's and target's capital stocks. Thus, the optimization program can be reduced to a 1-dimensional one, with the state variable given by the ratio of the stochastic valuations of the bidder's and target's capital. The value of total takeover gain in equation (3) can be rewritten as

$$
\begin{aligned}
G^{C}\left(X_{\mathrm{TRUE}}, Y\right) & =Y G^{C}\left(\frac{X_{\mathrm{TRUE}}}{Y}, 1\right)=Y G^{C}\left(\frac{X[1+\varepsilon]}{Y}, 1\right) \\
& =Y G^{C}(R[1+\varepsilon, 1]) \\
& =Y\left[\alpha K_{T}(R\{1+\varepsilon\}-1)-c\left(K_{B} R\{1+\varepsilon\}+K_{T}\right)\right],
\end{aligned}
$$

where $R=X / Y$.

We first solve the bidder's optimization problem while assuming an exogenous fraction of takeover surplus accruing to the bidder, $\xi$. We then solve the target's optimization problem assuming exogenous $\xi$. Finally, we find the equilibrium sharing rule by ensuring that the bidder and target have the same takeover thresholds.

The public bidder solves the following optimization program:

$$
\begin{aligned}
R_{B_{\mathrm{PUB}}}^{*} & =\arg \max _{R}\left(Y_{0} O_{\mathrm{PUB}}^{B}\left(R_{0}, \varepsilon, \xi\right)\right) \\
& =\arg \max _{R}\left\{\left(\frac{R_{0}}{R}\right)^{\beta}\left[\xi \alpha K_{T}(R\{1+\varepsilon\}-1)-c K_{B} R(1+\varepsilon)\right]\right\},
\end{aligned}
$$

where $R_{B_{\mathrm{PUB}}}^{*}$ is the bidder's optimal restructuring threshold, $Y_{0} O_{\mathrm{PUB}}^{B}\left(R_{0}, \varepsilon, \xi\right)$ is the value of its restructuring option given the current value of $R, R_{0}$, and $\beta$ is the positive root of the following quadratic equation:

$$
\frac{1}{2}\left(\sigma_{X}^{2}-2 \rho \sigma_{X} \sigma_{Y}+\sigma_{Y}^{2}\right) \beta(\beta-1)+\left(\mu_{X}-\mu_{Y}\right) \beta-r+\mu_{Y}=0 .
$$

The value of the merger option is a function of the valuation error, $\varepsilon$, the share of the combined surplus accruing to the bidder's shareholders, $\xi$, and the current value of $R$. We show in the Appendix that the optimal restructuring policy of the public bidder, obtained as a solution to expression (7), is to merge at the 1st time $R=X / Y$ reaches a threshold $R_{B_{\mathrm{PUB}}}^{*}$ from below, given by

$$
R_{B_{\mathrm{PUB}}}^{*}=\frac{\beta}{\beta-1} \frac{\xi \alpha K_{T}}{\left(\xi \alpha K_{T}-c K_{B}\right)(1+\varepsilon)} .
$$


Similar to expression (7), for a given sharing rule, the target maximizes the value of its restructuring option, $O_{\mathrm{PUB}}^{T}\left(X_{0}, Y_{0}, \varepsilon, \xi\right)$ :

$$
\begin{aligned}
R_{T_{\mathrm{PUB}}}^{*} & =\arg \max _{R}\left(Y_{0} O_{\mathrm{PUB}}^{T}\left(R_{0}, \varepsilon, \xi\right)\right) \\
& =\arg \max _{R}\left\{\left(\frac{R_{0}}{R}\right)^{\beta}\left[(1-\xi) \alpha K_{T}(R\{1+\varepsilon\}-1)-c K_{T}\right]\right\},
\end{aligned}
$$

where $R_{T_{\mathrm{PUB}}}^{*}$ is the optimal restructuring threshold of a target being acquired by a public bidder. The solution of the target's program in expression (10) results in the target's optimal restructuring strategy. This strategy is to merge at the 1st time the stochastic process $R=X / Y$ reaches $R_{T_{\mathrm{PUB}}}^{*}$ from below, given by

$$
R_{T_{\mathrm{PUB}}}^{*}=\frac{\beta}{\beta-1} \frac{(1-\xi) \alpha+c}{(1-\xi) \alpha(1+\varepsilon)},
$$

where $\beta$ is given in equation (8).

Note that the bidder's optimal restructuring threshold, $R_{B_{\mathrm{PUB}}}^{*}$, is decreasing in the fraction of the takeover surplus it is entitled to, $\xi$. When the bidder receives a higher proportion of combined equity, it is willing to speed up the exercise of the restructuring option. Similarly, the target's optimal restructuring threshold is increasing in $\xi$ (decreasing in $[1-\xi]$ ). Both $R_{B_{\mathrm{PUB}}}^{*}$ and $R_{T_{\mathrm{PUB}}}^{*}$ are decreasing in the valuation surprise, $\varepsilon$, because the value of the overall takeover gain is increasing in $\varepsilon$.

In the equilibrium that maximizes the combined value of the bidder's and target's options to merge, the optimal bidder's and target's restructuring thresholds coincide. The equilibrium merger threshold can be found by equating expression (9) with expression (11):

$$
R_{B_{\mathrm{PUB}}}^{*}=R_{T_{\mathrm{PUB}}}^{*}\left(\equiv R_{\mathrm{PUB}}^{*}\right) .
$$

Solving expression (12) for $\xi$ yields the equilibrium fraction of the merger surplus accruing to the bidder, $\xi^{*}$ :

$$
\xi^{*}=\frac{K_{B}}{K_{T}+K_{B}} \frac{\alpha+c}{\alpha},
$$

and the equilibrium merging threshold, $R_{\mathrm{PUB}}^{*}$ for the case of public bidder:

$$
R_{\mathrm{PUB}}^{*}=\frac{\beta}{\beta-1} \frac{(\alpha+c) K_{T}}{\left(\alpha K_{T}-c K_{B}\right)(1+\varepsilon)} .
$$

Equation (13) shows that 2 factors affect the equilibrium allocation of the merger surplus to the bidder's and target's shareholders: the firms' relative capital stocks and the benefit of the merger relative to its cost. Equation (14) implies that the optimal restructuring policy depends on the valuation surprise, $\varepsilon$. The higher the $\varepsilon$, the higher the true per-unit-of-capital value of the bidder's capital stock, $X_{\mathrm{TRUE}}=X(1+\varepsilon)$, the larger the restructuring gain (which depends on the difference between $X_{\text {TRUE }}$ and $Y$ ), and the higher the value of the option to 
merge. This implies that the higher the $\varepsilon$, the lower the level of $R_{\mathrm{PUB}}^{*}$ at which the merging firms exercise their restructuring option. Importantly, for any $\alpha$ satisfying $\alpha K_{T}-c K_{B}>0$, there is a threshold, $R_{\mathrm{PUB}}^{*}$, such that when $R=X / Y$ reaches it, a merger occurs.

An important quantity in our analysis is the value of the option to merge. As we show later, the difference between the value of this option for a public bidder and that for a private bidder determines the optimal decision of whether (and when) to go public. The value of the option to merge depends on whether the stochastic shock is sufficiently high that the firms should merge immediately, or it is not high enough, in which case it is optimal to wait. We show in the Appendix that in the latter case, in which the current state of the stochastic shock, $R_{0}$, is below the equilibrium restructuring threshold, $R_{\mathrm{PUB}}^{*}$, the present value of the public bidder's option to merge is given by

$$
\begin{aligned}
O_{\mathrm{PUB}}^{B}\left(R_{0}, \varepsilon\right)=Y_{0} & \frac{1}{\beta-1}\left[\frac{R_{0}(1+\varepsilon)(\beta-1)}{\beta} \frac{\alpha K_{T}-c K_{B}}{(\alpha+c) K_{T}}\right]^{\beta} \\
& \times \frac{(\alpha+c) K_{B} K_{T}}{K_{B}+K_{T}} .
\end{aligned}
$$

It is also important to note that the market value of the public bidder, $V_{\mathrm{PUB}}^{B}$, is different from the stand-alone value of its capital because the former takes into account the value of the option to merge:

$$
\begin{aligned}
V_{\mathrm{PUB}}^{B}\left(R_{0}, \varepsilon\right)= & Y_{0}\left\{K_{B} R_{0}(1+\varepsilon)\right. \\
& \left.+\frac{1}{\beta-1}\left[\frac{R_{0}(1+\varepsilon)(\beta-1)}{\beta} \frac{\alpha K_{T}-c K_{B}}{(\alpha+c) K_{T}}\right]^{\beta} \frac{(\alpha+c) K_{B} K_{T}}{K_{B}+K_{T}}\right\} .
\end{aligned}
$$

The takeover gain is a function of per-unit values of the bidder's and target's capital. In our model, in which there is no parameter uncertainty for public firms, per-unit-capital valuations can be backed out unambiguously from firms' market values.

If $R_{0}$ exceeds $R_{\mathrm{PUB}}^{*}$, then it is optimal to merge immediately, and the value of the bidder's option to merge (which equals the takeover gain) is given by

$$
O_{\mathrm{PUB}}^{B}\left(R_{0}, \varepsilon\right)=Y_{0}\left[R_{0}(1+\varepsilon)\left(\alpha K_{T}-c K_{B}\right)-(\alpha+c) K_{T}\right] \frac{K_{B}}{K_{B}+K_{T}} .
$$

As expected, the value of the bidder's option to merge is increasing in the valuation error, $\varepsilon$, and in the synergy parameter, $\alpha$, and is decreasing in the merger cost parameter, $c$.

\section{Acquisition by Private Bidder}

We now turn to the optimal restructuring threshold of the private bidder, which does not know the precise value of $X_{\mathrm{TRUE}}$, but knows that it is a random variable with known distribution. As in the public bidder case, the private bidder's 
objective is to maximize the present value of its option to merge with the target, $O_{\mathrm{PR}}^{B}$, by choosing the optimal merging threshold, $R_{B \mathrm{PR}}^{*}$ :

$$
\begin{aligned}
R_{B_{\mathrm{PR}}}^{*} & =\arg \max _{R} \mathbb{E}_{\varepsilon}\left(Y_{0} O_{\mathrm{PR}}^{B}\left(R_{0}, \xi\right)\right) \\
& =\arg \max _{R}\left\{\left(\frac{R_{0}}{R}\right)^{\beta} \mathbb{E}_{\varepsilon}\left(\xi \alpha K_{T}[R(1+\varepsilon)-1]-c K_{B} R[1+\varepsilon]\right)\right\} \\
& =\arg \max _{R}\left\{\left(\frac{R_{0}}{R}\right)^{\beta}\left[\xi \alpha K_{T}(R-1)-c K_{B} R\right]\right\},
\end{aligned}
$$

where $\mathbb{E}_{\varepsilon}$ denotes expectation over the distribution of $\varepsilon$. Similarly, the target maximizes the value of its share of the takeover surplus by solving the following optimization program:

$$
\begin{aligned}
R_{T_{\mathrm{PR}}}^{*} & =\arg \max _{R} \mathbb{E}_{\varepsilon}\left(Y_{0} O_{\mathrm{PR}}^{T}\left(R_{0}, \xi\right)\right) \\
& =\arg \max _{R}\left\{\left(\frac{R_{0}}{R}\right)^{\beta} \mathbb{E}_{\varepsilon}\left([1-\xi] \alpha K_{T}[R(1+\varepsilon)-1]-c K_{T}\right)\right\} \\
& =\arg \max _{R}\left\{\left(\frac{R_{0}}{R}\right)^{\beta}\left[(1-\xi) \alpha K_{T}(R-1)-c K_{T}\right]\right\} .
\end{aligned}
$$

The equilibrium is constructed in the same way as in the case of a public bidder discussed previously. The equilibrium merging threshold is now given by

$$
R_{\mathrm{PR}}^{*}=\frac{\beta}{\beta-1} \frac{(\alpha+c) K_{T}}{\alpha K_{T}-c K_{B}},
$$

whereas the equilibrium share of the private bidder in the merged entity is the same as in the public bidder case and is given by equation (13).

Similar to the public bidder case, the value of the private bidder's option to merge is given by

$$
O_{\mathrm{PR}}^{B}\left(R_{0}\right)=Y_{0} \frac{1}{\beta-1}\left[\frac{R_{0}(\beta-1)}{\beta} \frac{\alpha K_{T}-c K_{B}}{(\alpha+c) K_{T}}\right]^{\beta} \frac{(\alpha+c) K_{B} K_{T}}{K_{B}+K_{T}},
$$

if the current state of the stochastic shock, $R_{0}$, is below the equilibrium restructuring threshold $R_{\mathrm{PR}}^{*}$. If $R_{0}$ exceeds $R_{\mathrm{PR}}^{*}$, then it is optimal to merge immediately, and the value of the option to merge equals

$$
O_{\mathrm{PR}}^{B}\left(R_{0}\right)=Y_{0}\left[R_{0}\left(\alpha K_{T}-c K_{B}\right)-(\alpha+c) K_{T}\right] \frac{K_{B}}{K_{B}+K_{T}} .
$$

The comparison of the equilibrium restructuring thresholds for the cases of public and private bidders, in equations (20) and (14), respectively, demonstrates that the private bidder is at an obvious disadvantage. It does not know its precise valuation, which affects the value of the potential merger gain. The private bidder is, thus, unable to optimally exercise its option to merge. In the presence of imperfect information, a merger involving the private bidder almost always happens 
either too early or too late. In particular, if $\varepsilon>0$, then the public bidder's optimal restructuring threshold, given in equation (14), is lower than that of the private bidder, given in equation (20). In this case, the private bidder underestimates the value of the potential takeover gain and exercises its restructuring option inefficiently late. The relation between the 2 thresholds is reversed for $\varepsilon<0$.

Because of the inefficient exercise of the option to merge, the private bidder has an incentive to go public and learn its true valuation parameter, $X_{\mathrm{TRUE}}$, and, equally importantly, to make itself known to the target. By eliminating the valuation uncertainty, the bidder can increase the value of its restructuring option. The decision of whether (and when) to go public is based on the trade-off between this benefit and the IPO cost. This trade-off is analyzed next. In the next section we show qualitatively that going public may be beneficial. The calibration exercise in Section III quantifies the value of the option to go public and shows that the economic significance of the option to perform an IPO is nontrivial.

\section{Optimal IPO Timing}

The private bidder can follow 1 of 2 possible strategies. It can either go public at some future date, pay the IPO cost, learn its valuation surprise, $\varepsilon$, and then merge optimally with the target; or, alternatively, it can merge blindly as a private firm. If it decides to go public, it maximizes the present value of the restructuring option net of the IPO cost by optimally choosing the timing of the IPO. The present value of its restructuring option net of the IPO cost is given by

$$
\begin{aligned}
O_{\mathrm{IPO}}^{B}\left(R_{0}\right) & =\sup _{R^{\mathrm{IPO}}} \mathbb{E}_{\tau}\left\{e^{-r \tau_{R^{\mathrm{IPO}}}} \mathbb{E}_{\varepsilon}\left(O_{\mathrm{PUB}}^{B}\left(R^{\mathrm{IPO}}, \varepsilon\right)-\eta K_{B} R^{\mathrm{IPO}}[1+\varepsilon]\right)\right\} \\
& =\sup _{R^{\mathrm{IPO}}} \mathbb{E}_{\tau}\left\{e^{-r \tau_{R^{\mathrm{IPO}}}}\left(\mathbb{E}_{\varepsilon} O_{\mathrm{PUB}}^{B}\left(R^{\mathrm{IPO}}, \varepsilon\right)-\eta K_{B} R^{\mathrm{IPO}}\right)\right\},
\end{aligned}
$$

where $O_{\mathrm{PUB}}^{B}\left(R^{\mathrm{IPO}}, \varepsilon\right)$ is the value of the option to merge if the bidder goes public at $R^{\mathrm{IPO}}$, given in equations (15) and (17) for different values of $\varepsilon$. The IPO decision takes the form of an upper threshold, $R^{\mathrm{IPO}}$, such that when $R=X / Y$ first reaches $R^{\mathrm{IPO}}$, the option to go public is exercised by paying the IPO cost. Here, $\tau_{R^{\mathrm{IPO}}}$ is a stopping time upon reaching the IPO threshold, $R^{\mathrm{IPO}}$.

If the bidder stays private, the value of its restructuring option, $O_{\mathrm{PR}}^{B}\left(R_{0}\right)$, is given by equation (21). Therefore, the net gain from going public is given by the difference between $O_{\mathrm{IPO}}^{B}\left(R_{0}\right)$ and $O_{\mathrm{PR}}^{B}\left(R_{0}\right)$ :

$$
\text { IPO_GAIN }=O_{\mathrm{IPO}}^{B}\left(R_{0}\right)-O_{\mathrm{PR}}^{B}\left(R_{0}\right) .
$$

If this gain is positive, the benefit of going public dominates the IPO cost, and going public prior to merging is the optimal strategy. Otherwise, the optimal solution is to stay private. We show in the calibration exercise later that the option to go public has nontrivial value for reasonable parameter values. In other words, the ability to exercise the restructuring option at an optimal time has an economically meaningful effect on firm value. In what follows, we derive the value of the restructuring option for a private bidder that decides to go public, $O_{\mathrm{IPO}}^{B}\left(R_{0}\right)$, for all possible values of the IPO threshold. The functional form of the gain from the IPO depends on its timing, determined by the IPO threshold, $R^{\mathrm{IPO}}$. In particular, there are 3 regions to be analyzed. 
Region 1. $R^{\mathrm{IPO}}<((\beta) /(\beta-1))\left(\left([\alpha+c] K_{T}\right) /\left(\alpha K_{T}-c K_{B}\right)\right)(1 /(1+\lambda))$

In this region, the option to merge is never exercised immediately after going public. A situation in which a merger announcement immediately follows the IPO is ruled out, since for any possible value of $\varepsilon$, the corresponding equilibrium merging threshold of a public bidder, $R_{\mathrm{PUB}}^{*}(\varepsilon)=(\beta /(\beta-1))\left(\left([\alpha+c] K_{T}\right) /\right.$ $\left.\left(\alpha K_{T}-c K_{B}\right)\right)(1 /(1+\varepsilon))$, is higher than the current state of $R, R^{\mathrm{IPO}}<R_{\mathrm{PUB}}^{*}(\varepsilon)$. Since an immediate merger is never optimal, going public in this region cannot be optimal either. The reason is that the expected present value of the IPO cost is proportional to $R_{\mathrm{IPO}}^{1-\beta}$, and is, thus, decreasing in $R_{\mathrm{IPO}}$. Thus, it is always better to wait at least until $R$ reaches the value of $(\beta /(\beta-1))\left(\left([\alpha+c] K_{T}\right) /\left(\alpha K_{T}-c K_{B}\right)\right)$ $(1 /(1+\lambda))$ before going public.

Region 2. $(\beta /(\beta-1))\left(\left([\alpha+c] K_{T}\right) /\left(\alpha K_{T}-c K_{B}\right)\right)(1 /(1+\lambda)) \leq R^{\mathrm{IPO}}<$ $(\beta /(\beta-1))\left(\left([\alpha+c] K_{T}\right) /\left(\alpha K_{T}-c K_{B}\right)\right)(1 /(1-\lambda))$

In this region, 2 scenarios are possible after the potential bidder goes public at $R^{\mathrm{IPO}}$ and learns its valuation surprise, $\varepsilon$. If the value of the stochastic process at IPO is higher than the merging threshold of the public bidder, $R^{\mathrm{IPO}} \geq$ $R_{\mathrm{PUB}}^{*}=(\beta /(\beta-1))\left(\left([\alpha+c] K_{T}\right) /\left(\alpha K_{T}-c K_{B}\right)\right)(1 /(1+\varepsilon))$, then it is optimal to exercise the restructuring option immediately following the IPO, and the value of the restructuring option is given by equation (17).

If, on the other hand, $R^{\mathrm{IPO}}<R_{\mathrm{PUB}}^{*}=(\beta /(\beta-1))\left(\left([\alpha+c] K_{T}\right) /\left(\alpha K_{T}-c K_{B}\right)\right)$ $(1 /(1+\varepsilon))$, then it is optimal to merge at a higher state of the stochastic process, $R_{\mathrm{PUB}}^{*}=(\beta /(\beta-1))\left(\left([\alpha+c] K_{T}\right) /\left(\alpha K_{T}-c K_{B}\right)\right)(1 /(1+\varepsilon))$, and the value of the merger option is given by equation (15). In this region, as $R^{\mathrm{IPO}}$ increases, the range of values of $\varepsilon$ for which the bidder's optimal merger threshold is below $R^{\mathrm{IPO}}$ shrinks.

Integrating the values of the public bidder's option to merge in equations (15) and (17) over all possible values of $\varepsilon$ and subtracting the IPO cost yields the following value of going public:

$$
\begin{aligned}
& O_{\mathrm{IPO}}^{B}\left(R_{0}\right)= \\
& \sup _{R_{\tau}^{\mathrm{IO}}} \mathbb{E}_{\tau}\left\{e ^ { - r \tau _ { R _ { \mathrm { IPO } } } } \left\{\int _ { \varepsilon = - \lambda } ^ { \varepsilon ^ { * } } \left(\frac{1}{2 \lambda} \frac{1}{\beta-1}\left[\frac{R^{\mathrm{IPO}}(1+\varepsilon)(\beta-1)}{\beta} \frac{\alpha K_{T}-c K_{B}}{(\alpha+c) K_{T}}\right]^{\beta}\right.\right.\right. \\
& \left.\quad \times \frac{[\alpha+c] K_{B} K_{T}}{K_{B}+K_{T}}\right) d \varepsilon \\
& +\int_{\varepsilon=\varepsilon^{*}}^{\lambda}\left(\frac{1}{2 \lambda}\left[R^{\mathrm{IPO}}(1+\varepsilon)\left(\alpha K_{T}-c K_{B}\right)-(\alpha+c) K_{T}\right] \frac{K_{B}}{K_{B}+K_{T}}\right) d \varepsilon \\
& \left.\left.\quad-\eta K_{B} R^{\mathrm{IPO}}\right\}\right\}
\end{aligned}
$$

where $\varepsilon^{*}$ is the value of $\varepsilon$ leading to the merger threshold, $R_{\mathrm{PUB}}^{*}$, in equation (14) to be equal to $R_{\tau}^{\mathrm{IPO}}: \varepsilon^{*}=(\beta /(\beta-1))\left(1 /\left(R^{\mathrm{IPO}}\right)\right)\left(\left([\alpha+c] K_{T}\right) /\left(\alpha K_{T}-c K_{B}\right)\right)-1$. 
The 1 st term in equation (25) refers to the case in which it is not optimal to exercise the restructuring option immediately after the IPO; the 2nd term refers to the case of immediate exercise of the merger option; and the 3rd term is the IPO cost. The result of integrating equation (25) is presented in the Appendix.

Region 3. $(\beta /(\beta-1))\left(\left([\alpha+c] K_{T}\right) /\left(\alpha K_{T}-c K_{B}\right)\right)(1 /(1-\lambda)) \leq R^{\mathrm{IPO}}$

In this region the option to go public is worthless. Regardless of the true value of $\varepsilon$, the optimal restructuring policy is to merge immediately, and the restructuring options of the private and public bidders have identical values. As a consequence, a merger-driven IPO will never be observed in this region.

In the next section we calibrate the model using data on IPOs and M\&As. This calibration exercise will guide us in the comparative statics analysis later, the goal of which is to examine the effects of the model's parameters on the timing of IPOs and mergers and on the likelihood of acquisitions following IPOs.

\section{Data, Model Calibration, and Empirical Predictions}

\section{A. Data and Calibration}

We obtain data on IPOs and M\&As from Thomson Financial's SDC New Issues and Mergers and Acquisitions databases, respectively. Our data set contains IPOs and takeover attempts that occurred between 1981 and 2007. To be included in our initial sample, a merger has to satisfy the following criteria:

i) The deal does not belong to any of the following categories: minority stake purchase, acquisition of remaining interest, acquisition of division, asset swap, divestiture, or spin-off.

ii) The deal is not an LBO.

The 1 st restriction ensures that an attempted transaction, if successful, would result in a change of corporate control. The 2 nd condition is meant to restrict the sample to mergers between firms with physical capital, which can be utilized more productively as a result of a merger, as opposed to pure change of control of a single firm with existing physical capital, as in the case of a typical LBO. Our final sample contains 11,257 successful and unsuccessful attempts to acquire public and private targets. ${ }^{7}$ In what follows we refer to both successful and unsuccessful acquisition attempts as mergers. ${ }^{8}$

To be included in the IPO sample, the company must perform an IPO on 1 of the 3 major exchanges, and must have a filing and/or issue date available in the SDC database. We define an IPO date as the filing date. If the latter is unavailable, we use the issue date as the IPO date. We exclude rights issues, unit issues, reverse LBOs, real estate investment trusts (REITs), closed-end funds, and American

\footnotetext{
${ }^{7}$ Because many of the model's parameters are calibrated using Center for Research in Security Prices (CRSP) and Compustat data, the number of observations used in computing the data moments is smaller in most cases.

${ }^{8}$ The results are robust to restricting the sample to successful mergers. Also, the results are robust to excluding hostile takeovers, as identified by SDC. These results are available from the authors.
} 
Depositary Receipts (ADRs). In addition, we exclude firms with an offer price of less than $\$ 1$ or with net proceeds of less than $\$ 1$ million. Finally, we require that IPO firms have accounting data available in the Compustat database. Our final sample contains 6,552 IPOs. The model's parameters are calibrated as follows.

\section{Valuation Surprise, $\varepsilon$}

We use 3 measures of valuation surprise. The 1st measure is the revision of the IPO offer price relative to the midpoint of the initial filing range. ${ }^{9}$ An offer price revision reflects learning that occurs during the registration period. The mean value of offer price revision in our sample is $0.6 \%$, the median is 0 , and the 5 th and 95 th percentiles are $-32.8 \%$ and $36.4 \%$, respectively.

The offer-price-revision-based measure of valuation surprise may be biased toward 0 for 2 reasons. First, the initial filing range already reflects some information about the firm, collected by underwriters during the due diligence process. Second, Hanley (1993), Bradley and Jordan (2002), and Ritter and Welch (2002) report that offer price revision is positively related to IPO underpricing, leading to the conclusion that the adjustment to public information in the offer price revision is only partial, consistent with Benveniste and Spindt's (1989) information acquisition model.

Because of this potential bias, we use the 2 nd measure of valuation surprise (the surprise component of IPO underpricing), measured as the unexpected portion of the newly public firm's 1st-day return. The 1st-day return reflects the difference between the firm's market valuation and its final (offer) valuation by the IPO underwriter. ${ }^{10}$ We use the unexpected component of underpricing because of the extant evidence that the distribution of 1st-day IPO returns does not have 0 mean (e.g., Beatty and Ritter (1986), Hanley (1993), and Loughran and Ritter (2004)). To gauge the surprise component of underpricing, each year we estimate predictive regressions of 1st-day returns as in Bradley and Jordan (2002), who show that up to $1 / 2$ of IPO underpricing is predictable, using all IPOs in the year preceding the firm's IPO:

$$
\operatorname{RET}_{i}=\alpha+\beta^{\prime} z_{i}+\varepsilon_{i}
$$

RET1 $1_{i}$ is firm $i$ 's 1 st-day post-IPO return, and $z_{i}$ is a vector of firm $i$ 's characteristics, which include share overhang (pre-IPO shares divided by shares filed), offer price revision, venture capital (VC) backing indicator, mean 1st-day return for all IPOs that occurred in the month preceding the firm's IPO, high-tech indicator, NASDAQ indicator, IPO market share of lead underwriter, natural logarithm of issue amount, cumulative return on the NASDAQ index for 3 weeks prior to the

\footnotetext{
${ }^{9}$ This definition of offer price revision is also employed by Bradley and Jordan (2002), Ljungqvist and Wilhelm (2003), and Lowry, Officer, and Schwert (2010), among others. We also attempted to control for the time variation of mean offer price revision by subtracting annual mean revision from each offer price revision, and for changes in market conditions during the offer period by subtracting market return over the offer period from the offer price revision. All of the results are robust to these definitions of valuation error.

${ }^{10}$ The results reported later are unaffected by measuring longer-term post-IPO returns in order to circumvent the effects of initial price support by IPO underwriters (e.g., Lowry et al. (2010)).
} 
IPO, reciprocal of midrange file price, and dual-class stock indicator variable. ${ }^{11}$ We then use estimated coefficients from equation (26) to construct expected and unexpected components of 1st-day returns. The signs and significance levels of the coefficients in equation (26) are fully consistent with the results in Bradley and Jordan. ${ }^{12}$ The standard deviation of the surprise component of the 1 st-day return is $37.7 \%$, its mean is 0 by construction, its 5 th percentile is $-34.2 \%$, and its 95 th percentile is $46.7 \%$.

Our 3rd measure of valuation surprise combines the offer price revision and the unexpected part of the 1st-day return. Consistent with the evidence in Hanley (1993) and Bradley and Jordan (2002) and the unreported results of estimating equation (26) for our sample period, offer price revision and underpricing are positively correlated. The standard deviation of the $3 \mathrm{rd}$ measure of valuation surprise is $51.2 \%$, and its 5 th and 95 th percentiles are $-50.6 \%$ and $75 \%$, respectively.

\section{Valuation Uncertainty, $\lambda$}

In the model, the distribution of the valuation surprise, $\varepsilon$, is uniform, with bounds $-\lambda$ and $\lambda$. Since our 3 proxies for $\varepsilon$ are centered around 0 (their medians equal 0 and their means are insignificantly different from 0 ), we base our 3 proxies for $\lambda$ on the distributions of the absolute values of the 3 measures of $\varepsilon,|\varepsilon|$. Under the uniform distribution assumption, $E(|\varepsilon|)=\lambda / 2$. Thus, our estimate of $\lambda$ is $2 \overline{|\varepsilon|}$, where $\overline{|\varepsilon|}$ is the in-sample mean absolute valuation error, $\sum_{i}\left|\varepsilon_{i}\right| / n, n$ being the number of IPOs in our sample with information on offer price revision and/or unexpected portion of underpricing. The estimated values of the 3 measures of $\lambda$ are $29.4 \%, 37.2 \%$, and $55.8 \% .^{13}$

\section{IPO Cost, $\eta$}

We estimate the direct cost of going public as the ratio of the sum of the gross IPO spread and other direct expenses divided by the share overhang (the ratio of shares retained by nonselling shareholders to shares sold in the IPO). ${ }^{14}$ The reason for normalizing the IPO cost by share overhang is that the gross spread and direct expenses are computed relative to the value of newly issued equity. In our model, on the other hand, IPO cost is defined as a fraction of overall preissue firm value. The mean IPO cost relative to pre-IPO firm value, which we use as the estimate of $\eta$ in the calibration, is $1.56 \%$.

\section{Merger Cost, $c$}

We proxy for the cost of the merger by the sum of the after-tax restructuring cost and the combined bidder's and target's merger advisory fees, normalized

\footnotetext{
${ }^{11}$ See Bradley and Jordan (2002) for the definitions of independent variables in equation (26). Bradley and Jordan's model is also used in recent work by Kecskés (2008). Estimating a regression similar to equation (26) using control variables suggested by Loughran and Ritter (2004) provides results similar to those reported.

${ }^{12}$ The results of the estimation of equation (26) are available from the authors.

${ }^{13}$ Under uniform distribution, assumed in our model, the standard deviation of the valuation surprise is $\lambda / \sqrt{3}$. Thus, an alternative measure of $\lambda$ is $\sqrt{3}$ times the standard deviation of $\varepsilon$. The values of the 3 measures of $\lambda$ obtained this way are $28.8 \%, 40.6 \%$, and $55.7 \%$.

${ }^{14}$ See Chen and Ritter (2000) for an extensive study of gross spreads.
} 
by the bidder's and target's combined premerger market values. The restructuring cost averages $0.47 \%$ of the firms' premerger value in our sample, while the advisory fees average $0.22 \%$, resulting in the overall estimate of the cost of merger, $c$, of $0.69 \%$.

\section{Relative Target Size, $K_{T} / K_{B}$}

We proxy for the relative levels of the bidder's and target's capital by the ratio of their book assets at the end of the year preceding the acquisition announcement. The mean ratio of target's to bidder's book assets is 0.49 .

\section{Takeover Gain Factor, $\alpha$}

In the model, the takeover gain is described by $\alpha$, the bidder's ability to utilize the target's capital more productively. It follows from equation (3) that the increase in the combined bidder's and target's value equals the takeover gain net of its cost:

$$
\begin{aligned}
\alpha K_{T}\left(X_{\mathrm{TRUE}}-Y\right)-c\left(K_{B} X_{\mathrm{TRUE}}+K_{T} Y\right) & =\mathrm{RET}_{B} \mathrm{MV}_{B}+\mathrm{RET}_{T} \mathrm{MV}_{T} \\
& \equiv \mathrm{RET}_{B T} \mathrm{MV}_{T}
\end{aligned}
$$

where $\mathrm{RET}_{B}$ and $\mathrm{RET}_{T}$ are the bidder's and target's announcement returns, $\mathrm{MV}_{B}$ and $\mathrm{MV}_{T}$ are their preannouncement market values, and $\mathrm{RET}_{B T}$ is the combined bidder's and target's dollar return normalized by the target's market value. It follows from expression (27) that

$$
\alpha=\frac{\operatorname{RET}_{B T}+c}{\left(X_{\mathrm{TRUE}}-Y\right) / Y}+\frac{c K_{B} / K_{T}}{\left(X_{\mathrm{TRUE}}-Y\right) / X_{\mathrm{TRUE}}} .
$$

The value of productive capital is determined by the expected cash flows (profits) produced by it. Thus, capital valuation is expected to be related to profit per unit of capital (i.e., return on assets (ROA)). Therefore, we use the ratio of the bidder's and target's ROA at the end of the year preceding the takeover as a proxy for the relative valuation of their respective capital stocks, $X_{\mathrm{TRUE}}$ and $Y$. ROA is defined as the ratio of annual profit to beginning-of-year book assets. The mean bidder's ROA in our sample is 0.134 , while the mean ROA of public targets is 0.112 . The mean takeover gain relative to the target's value in our sample, $\operatorname{RET}_{B T}$, is $38 \%$. As discussed previously, the takeover cost, $c$, and the ratio of the target's size to the bidder's size, $K_{T} / K_{B}$, are estimated to be $0.69 \%$ and 0.49 , respectively. The resulting estimate of $\alpha$ is $2.06 .^{15}$

\section{Bidder's and Target's Drift Parameters, $\mu_{B}$ and $\mu_{T}$}

We estimate the bidder's and target's capital valuation drift parameters as the differences between the merging parties' payout yields and the typical riskfree rate during our sample period. We proxy for the mean risk-free rate by the yield on a 3-month T-bill averaged on a monthly basis throughout our sample

\footnotetext{
${ }^{15} \mathrm{~A}$ similar estimate of mean $\alpha$ is obtained when we use firms' relative market-to-book ratios instead of ROA as proxies for relative valuations of capital.
} 
period. The payout yield is computed as in Boudoukh, Michaely, Richardson, and Roberts (2007), as the sum of annual dividends, purchases of common and preferred stock, and reduction in the value of preferred stock outstanding, divided by the market value of equity at the beginning of the year. The mean 3-month T-bill yield equals $6.05 \%$. The mean payout yield of bidders (public targets) is $5.23 \%(5.45 \%)$. Our resulting estimates of $\mu_{B}$ and $\mu_{T}$ are $0.82 \%$ and $0.6 \%$, respectively.

\section{Bidder's and Target's Volatility and Correlation Parameters, $\sigma_{B}, \sigma_{T}$, and $\rho$}

In estimating $\sigma_{B}$ and $\sigma_{T}$, we follow Strebulaev (2007) and compute the standard deviation of unlevered monthly returns of each bidder and target in the year preceding the year of acquisition. Unlevered return is defined as the product of raw return and the ratio of the market value of equity to the sum of the market value of equity and the book value of debt. Since the autocorrelation of monthly returns is virtually 0 in our sample, to annualize our estimates we multiply each estimated standard deviation by $\sqrt{12}$. We then compute mean annual standard deviations of unlevered returns using all available observations for bidders and targets.

The correlation coefficient between the bidder's and target's stochastic processes, $\rho$, is estimated as the mean correlation between the bidder's and target's monthly returns in the year preceding the year of the merger, in cases where both series of monthly returns are available. Our resulting estimates of $\sigma_{B}, \sigma_{T}$, and $\rho$ are $24.7 \%, 26 \%$, and $18.4 \%$, respectively.

Table 1 summarizes our calibration exercise and the resulting estimates of the model's parameters. The table specifies the sample(s)/data source(s) used in calibration, mean values of the inputs used, and the number of available observations for each input.

\section{B. Comparative Statics and Empirical Predictions}

Equipped with calibrated parameters of the model, we proceed to examine the effects of these parameters on the IPO and restructuring thresholds. This analysis leads to empirical predictions regarding the determinants of the time that is expected to elapse between an IPO and subsequent merger. While the model features numerous parameters that could be used in comparative statics exercises, leading to empirical implications, we concentrate on core predictions regarding the effects of valuation uncertainty, realized valuation surprise, and IPO cost on the relative timing of IPOs and M\&As. As we discuss later, these predictions are unique to our model and distinguish it from alternative theories linking IPOs and acquisitions.

We begin by examining comparative statics of the restructuring threshold with respect to valuation surprise realized at the time of IPO for the base case of parameter values. The dashed line in Figure 1 represents merger threshold, while the solid line represents IPO threshold.

Clearly, the IPO threshold does not depend on the valuation surprise, as the latter is realized after the IPO has occurred. The merger threshold, on the other hand, is decreasing in the valuation surprise for $\varepsilon<0.38$, as discussed in the 


\section{TABLE 1}

\section{Calibration Summary}

Table 1 presents summary statistics from the calibration of the model parameters. The data sources are SDC for IPOs and M\&As, Compustat for accounting items, and CRSP for stock returns. Interest rate data are from http://www.federalreserve gov. The sample period is $1981-2007$. Here, $\varepsilon$ is the valuation error; $\lambda$ is the valuation uncertainty parameter; $\eta$ is the IPO cost; $\alpha$ is the takeover gain factor; $c$ is the merger cost; $K_{B} / K_{T}$ is the target's relative size; $\mu_{B}$ and $\mu_{T}$ are the drift parameters in the bidder's and target's valuation processes, respectively; $\sigma_{B}$ and $\sigma_{T}$ are the respective volatility parameters; and $\rho$ is the correlation between the 2 processes. Calibrated values refer to the result of the calibration and serve as the vector of base-case parameter values. The Inputs column presents the variables used in the calibration procedure for each parameter. The Mean column reports the average value of each of the included variables. The last column reports the number of observations used to estimate each variable.

\begin{tabular}{|c|c|c|c|c|c|}
\hline$\underline{\text { Parameter }}$ & $\begin{array}{c}\text { Calibrated } \\
\text { Value } \\
\end{array}$ & $\begin{array}{c}\text { Samples/ } \\
\text { Databases Used } \\
\end{array}$ & Inputs & Mean & $\begin{array}{l}\text { No. of } \\
\text { Obs. }\end{array}$ \\
\hline$\varepsilon$ & & & $\begin{array}{l}\text { offer price revision } \\
\text { unexpected 1st-day return }\end{array}$ & 0.006 & 6,552 \\
\hline$\lambda$ & 0.56 & IPOs & $|\varepsilon|$ & 0.28 & 6,552 \\
\hline$\eta$ & $1.56 \%$ & IPOs & $\begin{array}{l}\text { gross spread and expenses } \\
\text { share overhang }\end{array}$ & $\begin{array}{l}7.92 \% \\
5.08\end{array}$ & $\begin{array}{l}6,552 \\
6,552\end{array}$ \\
\hline$\alpha$ & 2.06 & $\begin{array}{l}\text { M\&As } \\
\text { Compustat } \\
\text { CRSP }\end{array}$ & $\begin{array}{c}\mathrm{ROA}_{B} \\
\mathrm{ROA}_{T} \\
\text { announcement return }\end{array}$ & $\begin{array}{l}0.134 \\
0.112 \\
38 \%\end{array}$ & $\begin{array}{l}5,005 \\
3,230 \\
2,533\end{array}$ \\
\hline c & $0.69 \%$ & $\begin{array}{c}\text { M\&As } \\
\text { Compustat }\end{array}$ & $\begin{array}{c}\text { after-tax restructuring costs } \\
(\text { adv. fees } B+\text { adv. fees } T) /\left(\mathrm{MA}_{B}+\mathrm{MA}_{T}\right)\end{array}$ & $\begin{array}{l}0.47 \% \\
0.22 \%\end{array}$ & $\begin{array}{l}1,296 \\
1,668\end{array}$ \\
\hline$K_{T} / K_{B}$ & 0.49 & $M \& A s$ & $\mathrm{BA}_{T} / \mathrm{BA}_{B}$ & 0.49 & 2,787 \\
\hline$\mu_{B}$ & $0.82 \%$ & $M \& A s$ & $Y_{\text {TBILL }}$ & $6.05 \%$ & 348 \\
\hline$\mu_{T}$ & $0.60 \%$ & $\begin{array}{l}\text { Compustat } \\
\text { Fed } \mathrm{H} 15 \text { report }\end{array}$ & $\begin{array}{l}\text { YPAYOUTB } \\
\text { YPAYOUTT }\end{array}$ & $\begin{array}{l}5.24 \% \\
5.45 \%\end{array}$ & $\begin{array}{l}4,221 \\
2,219\end{array}$ \\
\hline$\sigma_{B}$ & $24.71 \%$ & $M \& A s$ & $\operatorname{std}\left(R_{B}\left(1-\left(M E_{B} / M A_{B}\right)\right)\right)$ & $7.13 \%$ & 5,005 \\
\hline$\sigma_{T}$ & $26.04 \%$ & $\begin{array}{l}\text { Compustat } \\
\text { CRSP }\end{array}$ & $\operatorname{std}\left(\mathrm{R}_{T}\left(1-\left(\mathrm{ME}_{T} / \mathrm{MA}_{T}\right)\right)\right)$ & $7.52 \%$ & 3,230 \\
\hline$\rho$ & $18.38 \%$ & $\begin{array}{l}\text { M\&As } \\
\text { CRSP }\end{array}$ & $\begin{array}{l}\operatorname{corr}\left(R_{B}\left(1-\left(\mathrm{ME}_{B} / \mathrm{MA}_{B}\right)\right.\right. \\
\left.\quad R_{T}\left(1-\left(\mathrm{ME}_{T} / \mathrm{MA}_{T}\right)\right)\right)\end{array}$ & $18.38 \%$ & 2,032 \\
\hline
\end{tabular}

\section{FIGURE 1}

\section{Optimal IPO and Takeover Thresholds and Valuation Surprise}

Figure 1 plots the optimal merger threshold of a public bidder, $R_{\mathrm{PUB}}^{*}$, as a function of the valuation surprise realized at the time of IPO, $\varepsilon$ (dashed line). The solid line is the optimal IPO threshold, $R^{\mathrm{IPO}}$. Parameter values are set as in the base-case environment: $\lambda=0.558, \eta=1.54, \alpha=2.06, c=0.0069, K_{B}=1, K_{T}=0.49, \mu X=0.0082, \mu Y=0.006, \sigma X=0.247$, $\sigma Y=0.26, r=0.0605$, and $\rho=0.18$.

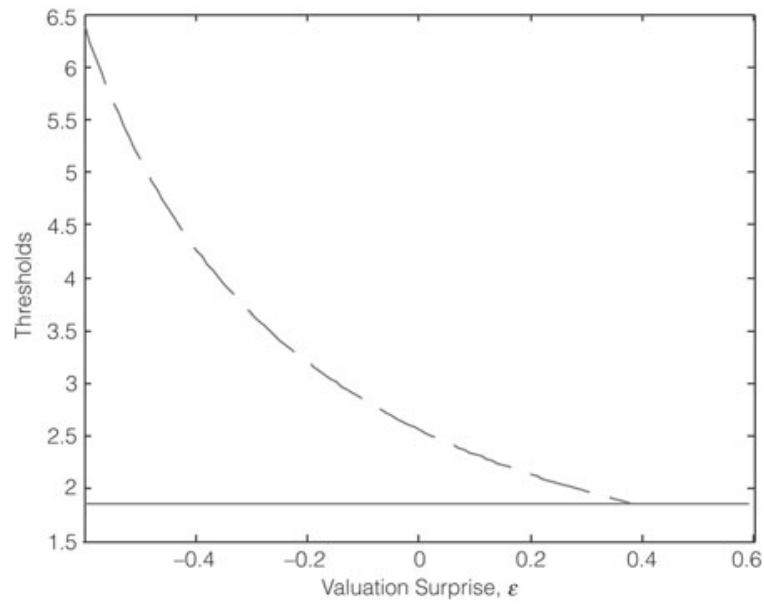


previous section. For $\varepsilon \geq 0.38$, on the other hand, the merger occurs immediately after IPO. This is because for high levels of $\varepsilon$, the value of the stochastic process $R$ at the time of the IPO, $R^{\mathrm{IPO}}$, is higher than the optimal restructuring threshold, $R_{\mathrm{PUB}}^{*}$. For slightly lower levels of $\varepsilon$, an immediate merger is not optimal, but it is likely that $R$ will reach $R_{\mathrm{PUB}}^{*}$ soon after the IPO.

Figure 1 leads to the 1 st empirical prediction:

Prediction 1. i) When a merger follows an IPO, the time between the IPO and merger is expected to be decreasing in the valuation surprise realized at the time of the IPO. ii) The likelihood of observing a post-IPO merger within a given time period is expected to be increasing in the valuation surprise. ${ }^{16}$

To examine the economic significance of the effect of valuation surprise on the timing of a post-IPO merger, in Table 2 we compute the probability of observing a post-IPO merger for various levels of $\varepsilon$ within a certain time following IPO $(1,2,3$, and 5 years), keeping the other parameters of the model at their base level.

TABLE 2

\section{Calibrated Likelihood of Post-IPO Merger and Valuation Error}

Table 2 presents the estimates of the likelihood of a merger occurring within certain time periods following an IPO (1, 2, 3 , and 5 years), as a function of valuation surprise realized at the time of IPO, $\varepsilon$. See Section III.C for detailed descriptions of the calibration procedure. The likelihood of merger is estimated using the calibrated parameter values reported in Table 1.

\begin{tabular}{lllll}
\multicolumn{1}{c}{$\varepsilon$} & \multicolumn{3}{c}{$\%$ Merger } \\
\cline { 2 - 5 }-0.558 & $\frac{1 \text { Year }}{2 \text { Years }}$ & $\frac{3 \text { Years }}{5 \text { Years }}$ \\
-0.372 & 0.0001 & 0.0032 & 0.0131 & 0.0428 \\
-0.186 & 0.0054 & 0.0401 & 0.0821 & 0.1518 \\
0 & 0.0593 & 0.1602 & 0.2314 & 0.3197 \\
0.186 & 0.2389 & 0.3759 & 0.4479 & 0.5252 \\
0.372 & 0.5617 & 0.6600 & 0.7049 & 0.7500 \\
0.558 & 0.9668 & 0.9746 & 0.9781 & 0.9815 \\
\hline
\end{tabular}

\footnotetext{
${ }^{16}$ The probability density function for the distribution of times between an IPO and subsequent merger is$$
f(t)=\frac{\ln \left(R_{\mathrm{PUB}}^{*} / R^{\mathrm{IPO}}\right)}{\sigma \sqrt{2 \pi} t^{3 / 2}}\left(\frac{R_{\mathrm{PUB}}^{*}}{R^{\mathrm{IPO}}}\right)^{\frac{\mu-\sigma^{2} / 2}{\sigma^{2}}} \exp \left(-\frac{\mu-\sigma^{2} / 2}{2}-\frac{\ln ^{2}\left(R_{\mathrm{PUB}}^{*} / R^{\mathrm{IPO}}\right)}{2 \sigma^{2} t}\right)
$$

if $R_{\mathrm{PUB}}^{*}>R^{\mathrm{IPO}}$ and $f(t)=\delta(t)$ if $R_{\mathrm{PUB}}^{*}<R^{\mathrm{IPO}}$, where $\delta(t)$ is Dirac's delta function. The resulting cumulative distribution function $(\mathrm{CDF})$ is

$$
\begin{aligned}
F(t)= & {\left[\left(\frac{R_{\mathrm{PUB}}^{*}}{R^{\mathrm{POO}}}\right)^{\frac{\mu-\sigma^{2} / 2}{\sigma^{2}}} \exp \left(-\frac{\mu-\sigma^{2} / 2}{2}\right) \pi^{1 / 2}-\ln ^{3}\left(\frac{R_{\mathrm{PUB}}^{*}}{R^{\mathrm{IPO}}}\right)\left(\operatorname{erf}\left(\frac{2^{1 / 2} \ln \left(\frac{R_{\mathrm{PVB}}^{*}}{R^{\mathrm{PO}}}\right)}{\sigma^{1 / 2}}\right)-1\right)\right] } \\
& {\left[\pi^{1 / 2} \ln ^{3}\left(\frac{R_{\mathrm{PUB}}^{*}}{R^{\mathrm{IPO}}}\right)\right] }
\end{aligned}
$$

if $R_{\mathrm{PUB}}^{*}>R^{\mathrm{IPO}}$ and $F(t)=1$ if $R_{\mathrm{PUB}}^{*}<R^{\mathrm{IPO}}$. The 1 st derivative of this CDF with respect to $R_{\mathrm{PUB}}^{*} / R^{\mathrm{IPO}}$ is negative (the proof is available from the authors); therefore, the likelihood of observing a merger at or before time $t$ is decreasing in $R_{\mathrm{PUB}}^{*} / R^{\mathrm{IPO}}$. 
Consistent with the results in Figure 1, Table 2 shows that higher valuation surprise increases the probability of a merger in 1- to 5-year time frames. As the value of $\varepsilon$ approaches the critical threshold of 0.38 , the probabilities of a merger in all time frames converge to 1 . As discussed previously, for $\varepsilon>0.38$, an immediate merger is optimal.

Next, we examine the comparative statics of the IPO threshold, $R^{\mathrm{IPO}}$, and the merger threshold of a private bidder, $R_{\mathrm{PR}}^{*}$, with respect to the degree of valuation uncertainty, $\lambda$. Note that $R_{\mathrm{PR}}^{*}$ also corresponds to the restructuring threshold of a public bidder whose valuation error, $\varepsilon$, equals 0 .

The solid line in Figure 2 represents the optimal IPO threshold, if going public is the optimal strategy. The dashed line represents the takeover threshold of a private bidder (or, alternatively, the takeover threshold of a public bidder with valuation surprise $\varepsilon=0$ ). Note that the takeover threshold is not a function of valuation uncertainty, $\lambda$. On the other hand, valuation uncertainty is a key determinant of the decision of whether and when to go public. It is worth going through a costly IPO in order to learn the value of a potential merger gain only if there is indeed something valuable to be learned, that is, if there is sufficient uncertainty regarding the true value of a potential bidder's capital stock (and the corresponding merger gain should the bidder decide to acquire the target). An increase in $\lambda$ raises the probability of high valuation surprise (and the probability that the optimal merger threshold is low) and, therefore, increases the cost of waiting, making an earlier IPO more attractive. Consistent with this logic, Figure 2 shows a negative relation between $\lambda$ and the IPO threshold.

\section{FIGURE 2}

\section{Optimal IPO and Takeover Thresholds and Valuation Uncertainty}

Figure 2 plots the optimal IPO threshold, $R^{\mathrm{IPO}}$, as a function of the degree of valuation uncertainty, $\lambda$ (solid line). The dashed line is the optimal merging threshold for the private bidder case, $R_{\mathrm{PR}}^{*}$. Parameter values are set as in the basecase environment (except for $\lambda$ ): $\eta=1.54, \alpha=2.06, c=0.0069, K_{B}=1, K_{T}=0.49, \mu_{X}=0.0082, \mu_{Y}=0.006$, $\sigma_{X}=0.247, \sigma_{Y}=0.26, r=0.0605$, and $\rho=0.18$.

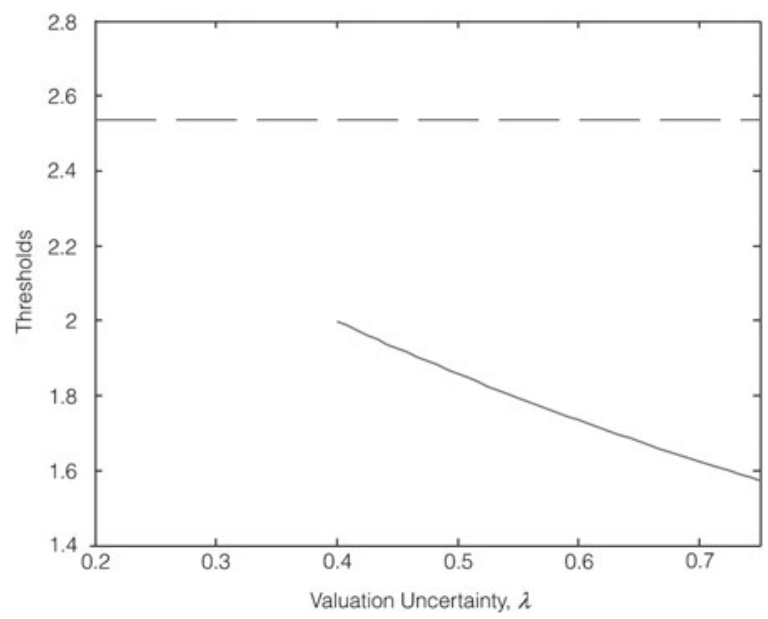


For the base-case set of parameter values, the critical value of the valuation uncertainty parameter is $\lambda=0.39$. Lower valuation uncertainty makes the IPO option unattractive because the benefit of learning $X_{\text {TRUE }}$ is lower than the IPO cost. When $\lambda$ is low, there is not much to be learned by going public, and the firm stays private. On the other hand, for $\lambda>0.39$, the value of the IPO's potential benefit is sufficiently high, and the firm prefers to go public. In that region, the optimal IPO threshold is decreasing in $\lambda$. The greater the valuation uncertainty, the greater the value of the option to learn the true value of the bidder, and the sooner this option is going to be exercised. Importantly, Figure 2 does not imply that there are no firms with $\lambda<0.39$ that find it optimal to go public. Firmspecific threshold $\lambda$ depends on all other parameter values and could be lower than $\lambda=0.39$.

Because the IPO threshold is decreasing in $\lambda$, while the average takeover threshold is independent of $\lambda$, increasing $\lambda$ widens the gap between the optimal IPO threshold and the (average) merger threshold, increases the time that is expected to elapse between the IPO and the merger attempt, and reduces the probability of a merger within a fixed time period following the IPO. Figure 2 leads to the following empirical prediction:

Prediction 2. i) When a merger follows an IPO, the time between the IPO and merger is expected to be increasing in the degree of valuation uncertainty. ii) The likelihood of a post-IPO merger within a given time period is expected to be decreasing in the degree of valuation uncertainty.

In order to examine the economic significance of valuation uncertainty on the likelihood and timing of a post-IPO merger, in Table 3, we compute the likelihood of a merger occurring within 1, 2, 3, and 5 years following the IPO for different combinations of the key model parameters: valuation uncertainty, $\lambda$, and the cost of going public, $\eta$. (The values of the rest of the parameters are kept at the base-case level.)

The effect of valuation uncertainty on the likelihood of observing a merger within a given time frame is significant. For example, when the cost of IPO, $\eta$, is kept at the base-case level (1.56), reducing the valuation uncertainty parameter, $\lambda$, by 0.1 relative to its base-case value of 0.558 results in an increase in the likelihood of a merger within 1 year of an IPO by almost 4 percentage points, from $39.0 \%$ to $42.9 \%$. Reducing $\lambda$ from 0.758 to 0.358 increases the probability of a merger within 5 years from $46.6 \%$ to $66.5 \%$. Relatively low information uncertainty $(\lambda=0.358)$ makes IPO unattractive for relatively high IPO cost $(2.56 \%$ and above), while an environment with very uncertain valuations $(\lambda=0.758)$ induces firms to go public even if IPO cost is as high as $4.56 \%$.

Another important determinant of the decision to go public is the IPO cost, $\eta$, as demonstrated in Figure 3.

Similar to Figure 2, the dashed line in Figure 3, representing the takeover threshold of a private bidder (or, alternatively, the takeover threshold of a public bidder with valuation surprise $\varepsilon=0$ ), is not a function of IPO cost, $\eta$, since at the time of the merger this cost is sunk. The optimal IPO threshold, $R^{\mathrm{IPO}}$, is increasing in $\eta$ : the costlier the IPO, the less eager the potential private bidder is to go public before attempting an acquisition. As noted in Section II, the expected present 
TABLE 3

Calibrated Likelihood of Post-IPO Merger, Valuation Uncertainty, and IPO Cost

Table 3 presents the estimates of the likelihood of a merger occurring within certain time periods following an IPO (1, 2, 3 , and 5 years). See Section III.C for detailed descriptions of the calibration procedure. The base case is estimated using the calibrated values in Table 1. The numbers in bold refer to the base-case scenario.

\begin{tabular}{|c|c|c|c|c|c|}
\hline \multirow[b]{2}{*}{$\lambda$} & \multirow[b]{2}{*}{$\eta$} & \multicolumn{4}{|c|}{$\%$ Merger } \\
\hline & & 1 Year & 2 Years & 3 Years & 5 Years \\
\hline 0.358 & $\begin{array}{l}0.56 \\
1.56 \\
2.56 \\
3.56 \\
4.56\end{array}$ & $\begin{array}{l}0.4221 \\
0.4930 \\
\text { No IPO } \\
\text { No IPO } \\
\text { No IPO }\end{array}$ & $\begin{array}{l}0.5073 \\
0.5710 \\
\text { No IPO } \\
\text { No IPO } \\
\text { No IPO }\end{array}$ & $\begin{array}{l}0.5563 \\
0.6150 \\
\text { No IPO } \\
\text { No IPO } \\
\text { No IPO }\end{array}$ & $\begin{array}{r}0.6127 \\
0.6647 \\
\text { No IPO } \\
\text { No IPO } \\
\text { No IPO }\end{array}$ \\
\hline 0.458 & $\begin{array}{l}0.56 \\
1.56 \\
2.56 \\
3.56 \\
4.56\end{array}$ & $\begin{array}{l}0.3658 \\
0.4291 \\
\text { No IPO } \\
\text { No IPO } \\
\text { No IPO }\end{array}$ & $\begin{array}{l}0.4425 \\
0.5007 \\
\text { No IPO } \\
\text { No IPO } \\
\text { No IPO }\end{array}$ & $\begin{array}{l}0.4895 \\
0.5441 \\
\text { No IPO } \\
\text { No IPO } \\
\text { No IPO }\end{array}$ & $\begin{array}{l}0.5467 \\
0.5962 \\
\text { No IPO } \\
\text { No IPO } \\
\text { No IPO }\end{array}$ \\
\hline 0.558 & $\begin{array}{l}0.56 \\
1.56 \\
2.56 \\
3.56 \\
4.56\end{array}$ & $\begin{array}{l}0.3264 \\
\mathbf{0 . 3 9 0 3} \\
0.4307 \\
\text { No IPO } \\
\text { No IPO }\end{array}$ & $\begin{array}{l}0.3951 \\
\mathbf{0 . 4 5 4 7} \\
0.4923 \\
\text { No IPO } \\
\text { No IPO }\end{array}$ & $\begin{array}{l}0.4384 \\
\mathbf{0 . 4 9 5 1} \\
0.5308 \\
\text { No IPO } \\
\text { No IPO }\end{array}$ & $\begin{array}{l}0.4931 \\
\mathbf{0 . 5 4 5 9} \\
0.5791 \\
\text { No IPO } \\
\text { No IPO }\end{array}$ \\
\hline 0.658 & $\begin{array}{l}0.56 \\
1.56 \\
2.56 \\
3.56 \\
4.56\end{array}$ & $\begin{array}{l}0.2910 \\
0.3579 \\
0.3892 \\
0.4244 \\
\text { No IPO }\end{array}$ & $\begin{array}{l}0.3535 \\
0.4164 \\
0.4453 \\
0.4784 \\
\text { No IPO }\end{array}$ & $\begin{array}{c}0.3932 \\
0.4536 \\
0.4808 \\
0.5126 \\
\text { No IPO }\end{array}$ & $\begin{array}{r}0.4443 \\
0.5014 \\
0.5264 \\
0.5565 \\
\text { No IPO }\end{array}$ \\
\hline 0.758 & $\begin{array}{l}0.56 \\
1.56 \\
2.56 \\
3.56 \\
4.56\end{array}$ & $\begin{array}{l}0.2778 \\
0.3329 \\
0.3667 \\
0.3957 \\
0.4196\end{array}$ & $\begin{array}{l}0.3357 \\
0.3871 \\
0.4185 \\
0.4456 \\
0.4679\end{array}$ & $\begin{array}{l}0.3725 \\
0.4215 \\
0.4514 \\
0.4773 \\
0.4986\end{array}$ & $\begin{array}{l}0.4201 \\
0.4660 \\
0.4939 \\
0.5183 \\
0.5383\end{array}$ \\
\hline
\end{tabular}

FIGURE 3

\section{Optimal IPO and Takeover Thresholds and IPO Cost}

Figure 3 plots the optimal IPO threshold, $R^{\mathrm{IPO}}$, as a function of the IPO cost $\eta$ (solid line). The dashed line is the optimal merging threshold for the private bidder case, $R_{\mathrm{PR}}^{*}$. Parameter values are set as in the base-case environment (except for $\eta$ ): $\lambda=0.558, \alpha=2.06, c=0.0069, K_{B}=1, K_{T}=0.49, \mu_{X}=0.0082, \mu_{Y}=0.006, \sigma_{X}=0.247, \sigma_{Y}=0.26$, $r=0.0605$, and $\rho=0.18$.

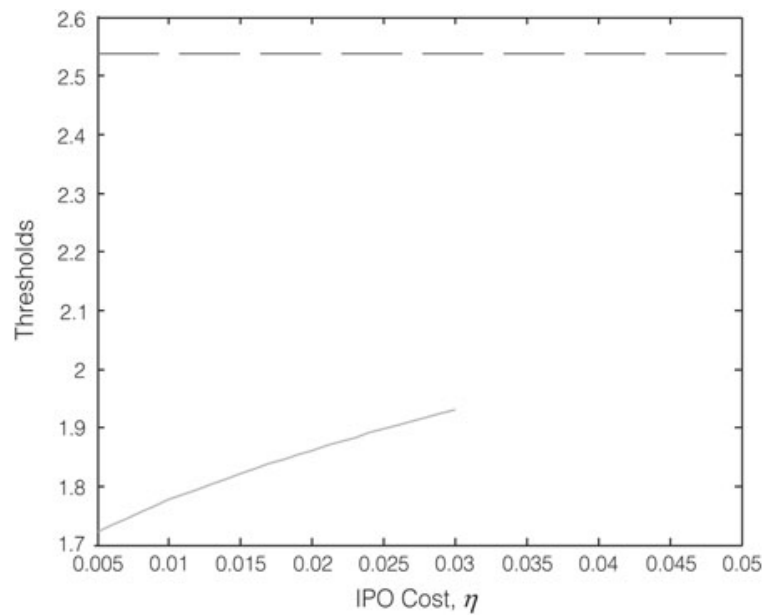


value of the IPO cost is decreasing in $R^{\mathrm{IPO}}$. As $\eta$ increases, the private bidder chooses to postpone its decision to go public in order to reduce the present value of the IPO cost. However, by postponing the IPO decision further, the bidder also reduces the benefit of going public, as it becomes more likely that the optimal time to merge, corresponding to the bidder's true value, $X_{\mathrm{TRUE}}$, has already passed, and the firm is bound to exercise its restructuring option inefficiently late. The optimal IPO timing is determined by the trade-off between these two effects.

For the typical set of parameter values, a regime shift occurs at $\eta=3 \%$. While it is optimal for a firm to go public before attempting a merger for values of $\eta$ below 3\%, for values of $\eta$ exceeding 3\% the IPO cost becomes too high relative to the benefit of learning the valuation error. Thus, for an average firm, being able to exercise the restructuring option optimally is not worth paying over $3 \%$ of its pre-IPO value. For high values of $\eta$, a potential bidder prefers to merge blindly at the restructuring threshold $R_{\mathrm{PR}}^{*}$ in order to save the cost of going public. The expected timing of a merger is not affected by IPO cost. However, IPO cost affects the optimal IPO timing. The larger the cost of going public, the longer the firm would wait before exercising its IPO option. Consequently, the expected time between IPO and merger is decreasing in the IPO cost, leading to the following empirical prediction:

Prediction 3. i) When an IPO precedes a merger attempt, the time between the IPO and merger is expected to be decreasing in the IPO cost. ii) The likelihood of observing a post-IPO merger is expected to be increasing in the IPO cost.

As evidenced from Table 3, the effect of IPO cost on the expected time that elapses between an IPO and a subsequent merger is economically significant. For example, increasing IPO cost, $\eta$, by 1 percentage point from its base-case level of $1.56 \%$ raises this probability of merger within 1 year by 4 percentage points, from $39.03 \%$ to $43.07 \%$. Relatively high IPO $\operatorname{cost}(\eta=4.56 \%)$ makes IPO unattractive for firms with relatively low valuation uncertainty $(0.658$ and below), while for the base value of IPO cost (1.56\%) firms with relatively low valuation uncertainty (0.358) go public prior to merging.

\section{Empirical Tests}

Predictions 1 and 2, discussed in the previous section, describe how valuation surprises realized at the time of IPO and the degree of pre-IPO valuation uncertainty affect a firm's post-IPO acquisition strategy. Importantly, these predictions do not follow from existing models of merger-driven IPOs, which do not examine the timing of post-IPO acquisitions. Prediction 3 is also unique to our model because in the cash infusion and asymmetric information theories, the cost paid at the time of IPO does not affect the timing of IPO and subsequent mergers. Thus, in these alternative models there is no link between the IPO cost and the time that is expected to pass between IPO and post-IPO acquisition. In our model, while the cost of going public does not affect the expected timing of a merger, it does affect the timing of IPO and, indirectly, the expected time that elapses between IPO and merger. 


\title{
Test of Prediction 1
}

Prediction 1 states that firms that realize higher valuation surprises are likely to attempt mergers sooner than firms that realize lower valuation errors. In Table 4 we examine the relation between valuation surprises and the likelihood and timing of post-IPO acquisitions, while controlling for variables that are likely to affect firms' merger activity. Panel A of Table 4 presents the results of estimating logistic regressions in which the dependent variable, $\mathbb{I}\left(\mathrm{MERGER}_{i}\right)$, is an indicator equal to 1 if a newly public firm attempted a merger within 60 months of its IPO, and 0 otherwise, and the independent variables are the 3 proxies for the valuation surprise revealed at the time of the IPO, $\varepsilon_{i}$ (offer price revision, unexpected component of IPO underpricing, and the combination of the two), and

\section{TABLE 4}

\section{Valuation Error and the Likelihood and Timing of Post-IPO Mergers}

\begin{abstract}
Panel A of Table 4 presents estimates from logistic regressions of merger likelihood during the 5-year period following an IPO on various measures of valuation surprise realized at the time of the IPO. Panel B reports estimates from duration models in which the dependent variable is the time until post-IPO merger, with merger events censored at 5 years (see Section IV for details). The sample consists of IPOs in years 1981-2002. Valuation error is defined as i) the revision of the offer price relative to the midpoint of the initial filing range, ii) the residual from the model that predicts the IPO 1st-day return (see Section III for details), or iii) the combination of i) and ii). C\&I rate spread is obtained from http://www.federalreserve.gov/releases/e2/e2chart.htm. Deregulatory event, documented in Harford (2005), is a dummy variable equal to 1 in the year following an industry deregulation event. Abnormal return is the average of returns net of CRSP value-weighted returns of firms in the IPO firm industry in the IPO year. Noncash working capital is defined as net working capital minus cash and cash equivalents, normalized by total assets. Leverage is the sum of short-term and longterm debt divided by total assets. MV/BV is the ratio of the market value of assets to the book value of assets. P/E ratio is the stock price at the end of the IPO year divided by earnings. Assets are total assets. Excess cash is the IPO firm's cash and cash equivalents minus the median value in the same industry. All accounting variables are from the IPO year, and p-values are reported in parentheses. Marginal effects of valuation errors are reported in square brackets in Panel A. Bold represents the main variable of interest.
\end{abstract}

Panel A. Logit Models

\begin{tabular}{lr}
\multicolumn{1}{c}{ Variable } & $(1)$ \\
\cline { 2 - 2 } Intercept & -6.618 \\
& $(0.000)$ \\
Valuation error $(\varepsilon)$ & 0.787 \\
& $(0.000)$ \\
C\&l rate spread & {$[0.126]$} \\
& -1.051 \\
Deregulatory event & $(0.000)$ \\
& 0.158 \\
Abnormal return & $(0.466)$ \\
& 2.909 \\
Noncash working capital & $(0.001)$ \\
& -0.353 \\
Leverage & $(0.021)$ \\
& -0.793 \\
MV/BV & $(0.001)$ \\
P/E ratio & 0.127 \\
In(Assets) & $(0.000)$ \\
Excess cash & -0.0002 \\
& $(0.814)$ \\
& 0.298 \\
& $(0.000)$ \\
& 0.111 \\
& $(0.569)$ \\
& 5,142 \\
& 0.092 \\
& \\
&
\end{tabular}

$$
\begin{gathered}
(2) \\
\hline-6.608 \\
(0.000) \\
0.242 \\
(0.004) \\
{[0.038]} \\
-0.998 \\
(0.000) \\
0.162 \\
(0.452) \\
2.484 \\
(0.002) \\
-0.370 \\
(0.016) \\
-0.903 \\
(0.000) \\
0.137 \\
(0.000) \\
-0.0001 \\
(0.906) \\
0.323 \\
(0.000) \\
0.199 \\
(0.306) \\
5,142 \\
0.089
\end{gathered}
$$

$$
\begin{gathered}
(3) \\
\hline-6.542 \\
(0.000) \\
0.301 \\
(0.000) \\
{[0.048]} \\
-1.005 \\
(0.000) \\
0.160 \\
(0.458) \\
2.840 \\
(0.001) \\
-0.373 \\
(0.015) \\
-0.845 \\
(0.000) \\
0.126 \\
(0.000) \\
-0.0001 \\
(0.896) \\
0.309 \\
(0.000) \\
0.168 \\
(0.388) \\
5,142 \\
0.091
\end{gathered}
$$


TABLE 4 (continued)

Valuation Error and the Likelihood and Timing of Post-IPO Mergers

\begin{tabular}{|c|c|c|c|}
\hline Variable & $(1)$ & $(2)$ & (3) \\
\hline Intercept & $\begin{array}{l}19.303 \\
(0.000)\end{array}$ & $\begin{array}{l}19.408 \\
(0.000)\end{array}$ & $\begin{array}{c}19.263 \\
(0.000)\end{array}$ \\
\hline Valuation error $(\varepsilon)$ & $\begin{array}{l}-1.270 \\
(0.000)\end{array}$ & $\begin{array}{l}-0.394 \\
(0.004)\end{array}$ & $\begin{array}{c}-0.475 \\
(0.000)\end{array}$ \\
\hline C\&I rate spread & $\begin{array}{l}2.935 \\
(0.000)\end{array}$ & $\begin{array}{l}2.887 \\
(0.000)\end{array}$ & $\begin{array}{c}2.889 \\
(0.000)\end{array}$ \\
\hline Deregulatory event & $\begin{array}{l}-0.116 \\
(0.752)\end{array}$ & $\begin{array}{l}-0.118 \\
(0.750)\end{array}$ & $\begin{array}{c}-0.115 \\
(0.755)\end{array}$ \\
\hline Abnormal return & $\begin{array}{l}-5.179 \\
(0.000)\end{array}$ & $\begin{array}{l}-4.632 \\
(0.000)\end{array}$ & $\begin{array}{c}-5.076 \\
(0.000)\end{array}$ \\
\hline Noncash working capital & $\begin{array}{c}0.765 \\
(0.003)\end{array}$ & $\begin{array}{c}0.798 \\
(0.002)\end{array}$ & $\begin{array}{c}0.797 \\
(0.002)\end{array}$ \\
\hline Leverage & $\begin{array}{c}1.060 \\
(0.006)\end{array}$ & $\begin{array}{c}1.255 \\
(0.001)\end{array}$ & $\begin{array}{c}1.154 \\
(0.003)\end{array}$ \\
\hline MV/BV & $\begin{array}{l}-0.206 \\
(0.000)\end{array}$ & $\begin{array}{l}-0.222 \\
(0.000)\end{array}$ & $\begin{array}{c}-0.203 \\
(0.000)\end{array}$ \\
\hline $\mathrm{P} /$ E ratio & $\begin{array}{c}0.001 \\
(0.608)\end{array}$ & $\begin{array}{c}0.001 \\
(0.683)\end{array}$ & $\begin{array}{c}0.001 \\
(0.687)\end{array}$ \\
\hline In(Assets) & $\begin{array}{l}-0.551 \\
(0.000)\end{array}$ & $\begin{array}{l}-0.593 \\
(0.000)\end{array}$ & $\begin{array}{c}-0.569 \\
(0.000)\end{array}$ \\
\hline Excess cash & $\begin{array}{l}-0.212 \\
(0.519)\end{array}$ & $\begin{array}{l}-0.363 \\
(0.270)\end{array}$ & $\begin{array}{c}-0.313 \\
(0.340)\end{array}$ \\
\hline $\begin{array}{l}\text { No. of obs. } \\
\text { Log likelihood }\end{array}$ & $\begin{array}{l}5,142 \\
-5,119.28\end{array}$ & $\begin{array}{l}5,142 \\
-5,129.08\end{array}$ & $\begin{array}{c}5,142 \\
-5,123.01\end{array}$ \\
\hline
\end{tabular}

a vector of additional variables that were found in past studies to affect firms' propensities to acquire other firms, $z_{i}:{ }^{17}$

$$
\mathbb{I}\left(\operatorname{MERGER}_{i}\right)=\frac{1}{1+e^{-\left(\alpha+\beta_{1} \varepsilon_{i}+\beta^{\prime} z_{i}\right)}} .
$$

Panel B of Table 4 reports the results of estimating duration (lifetime) models in which the dependent variable is the number of months that it takes a firm that went public to make a 1 st merger attempt. Here, $T_{i}$ denotes the time between a firm's IPO date and the earliest of i) a 1st post-IPO merger attempt, ii) the date when the firm disappeared from the sample, and iii) 60 months. An observation is considered uncensored if a firm merged with another firm within 60 months of its IPO. An observation is considered censored if a firm did not merge within 60 months of its IPO or if it disappeared from the sample within 5 years of the IPO. Here, $z_{i}$ denotes a vector of explanatory variables expected to be related to the time between IPO and 1st merger attempt. We estimate the parameters of the duration model by maximizing the following log-likelihood function:

$$
\ln L=\sum_{i=1}^{k} \ln f\left(T_{i}\right)+\sum_{i=k+1}^{N} \ln S\left(T_{i}\right),
$$

\footnotetext{
${ }^{17}$ The results reported here and later are robust to changing the definition of the post-IPO period to 12,24 , and 36 months and to including yearly fixed effects.
} 
where $k$ is the number of uncensored observations (i.e., the number of IPO firms that merged within 5 years of going public), $N$ is the number of firms that went public, $f\left(T_{i}\right)$ is the probability density function for the uncensored data, and $S\left(T_{i}\right)=1-F\left(T_{i}\right)$ is the survival function for censored data. We assume that $f\left(T_{i}\right)$ follows a Weibull distribution. ${ }^{18}$ Since we need to allow firms sufficient time to merge after their IPOs, the sample of firms used in the estimation of regressions in Table 4 includes all firms that performed an IPO in or before 2002.

The choice of control variables is motivated by both behavioral and neoclassical hypotheses of determinants of mergers, and generally follows Mitchell and Mulherin (1996) and Andrade and Stafford (2004). The controls include various IPO firm characteristics: book leverage, noncash working capital, market-tobook ratio, price-to-earnings $(\mathrm{P} / \mathrm{E})$ ratio, size, cash relative to the firm's industry median, and abnormal return in the 1st post-IPO year. Also, following Harford (2005), we include 2 additional control variables. The 1st variable is the spread between average commercial and industrial (C\&I) loan rates and the Fed rate (C\&I rate spread), which proxies for credit availability. The 2 nd variable is deregulation shock, proxied by a dummy variable that equals 1 following a deregulation of an industry. ${ }^{19}$

Each panel in Table 4 has 3 columns, corresponding to 3 measures of $\varepsilon$. The results of logistic regressions in Panel A are consistent with Prediction 1 of the model. The more positive the valuation surprise revealed at the time of an IPO, the larger the probability that a merger would occur within 5 years of the IPO. These results are strong and highly statistically significant for all 3 measures of valuation surprise, as evidenced by near- 0 -values. The economic effect of valuation surprise on the likelihood of observing a merger within 5 years of an IPO is also substantial. For example, as suggested by valuation surprise's marginal effect, the probability of observing a merger within 5 years of an IPO with valuation surprise falling into the 95th percentile $(\varepsilon=75 \%)$ is higher than the probability of a post-IPO merger for an IPO with valuation surprise falling into the 5 th percentile $(\varepsilon=-51 \%)$ by over 6 percentage points. In addition, the coefficients on all of the control variables are consistent with the underlying theories and aforementioned empirical papers examining the determinants of M\&As. For example, C\&I rate spread is negatively and significantly related to the likelihood of merger, while abnormal return, market-to-book ratio, and size are positively related to it.

The results of estimating duration models in Panel B of Table 4 are also consistent with the model. The larger the valuation surprise, the shorter the time it takes a newly public firm to attempt an acquisition. Naturally, the signs of the control variables are the opposite of those in Panel A. Overall, the evidence in Table 4 is strongly supportive of the 1st timing prediction of our model and provides the 1st piece of evidence that distinguishes our model from alternative, static models relating IPOs and mergers.

\footnotetext{
${ }^{18}$ The results are insensitive to assuming exponential, lognormal, or log-logistic distributions instead.

${ }^{19}$ See Table 4 for precise variable definitions. See Harford (2005) for the list of deregulation events.
} 


\section{Test of Prediction 2}

Prediction 2 suggests that more time is expected to pass between an IPO and subsequent merger for firms with higher degrees of valuation uncertainty. We use 3 measures of valuation uncertainty, $\lambda$, based on the 3 measures of valuation surprises discussed previously. An IPO firm's measure of valuation uncertainty is computed as twice the mean absolute value of 1 of the 3 valuation surprise measures of all firms going public in the firm's Fama and French (1997) industry in the year preceding the firm's IPO year. ${ }^{20}$

Equipped with measures of valuation uncertainty, we can estimate logistic regressions and duration models as in equations (29) and (30), while augmenting the regressions by measures of $\lambda$. One difficulty that we face, though, is that the degree of valuation uncertainty in an industry could be related to the volatility of a firm's profit process, which, in turn, can affect the optimal timing of investments in general (and acquisitions of other firms in particular) through channels unrelated to the restructuring-option-value channel proposed in this paper. These alternative channels are numerous. On one hand, because volatility increases the value of the option to wait (e.g., McDonald and Siegel (1986), Pindyck (1988), among many others), the larger the reduction in volatility following an IPO the faster all investments (and mergers in particular) are going to occur. On the other hand, adjustable production functions, possibility of bankruptcy, and abandonment options are consistent with the reduction of volatility leading to increased time until investment (e.g., Roberts and Weitzman (1981), Stiglitz and Weiss (1981), Abel (1983), and Leahy and Whited (1996)).

In order to separate the restructuring-option-value effect on the timing of post-IPO acquisitions from the other effects mentioned previously, we use a control firm approach. In particular, for each IPO firm we try to find a control firm having similar characteristics. Specifically, to minimize the benchmark bias, discussed in Loughran and Ritter (2000), for each IPO firm we locate all firms in the same Fama and French (1997) industry having total assets within 10\% of those of IPO firms that have been public for at least 5 years. If this initial subset contains fewer than 3 candidate firms, we expand the range of firm sizes to be within $20 \%$ of the IPO firm. We repeat this step of widening the potential size gap to $40 \%$ of that of the IPO firm if necessary. The firm with the closest market-to-book ratio among the potential matching firms is chosen as the control firm. For our sample of 6,552 IPO firms, we find matches for 5,515 firms.

We then estimate duration models of merger timing and logistic regressions of the probability of observing a merger within a certain time period using a combined sample of IPO firms and control firms, employing the following 2 independent variables. The 1st variable is the overall uncertainty in the industry, proxied by the estimate of the previous year's industry valuation uncertainty parameter, $\lambda$. The 2 nd variable is the interaction between the industry valuation uncertainty measure and a dummy variable equal to 1 for IPO firms, and 0 for control firms.

\footnotetext{
${ }^{20}$ This measure is based on the model specification in which valuation surprises are assumed to be uniformly distributed. Foregoing this parametric assumption and using the standard deviation of the previous year's valuation errors produces results very similar to those reported later.
} 
While we are agnostic about the sign of the coefficient on the measure of uncertainty, we expect the effect of the interaction variable (i.e., the effect of valuation uncertainty of IPO firms over and above overall valuation uncertainty) on the time until acquisition to be positive and its effect on the likelihood of observing a merger within a certain time period to be negative. The results are reported in Table 5, which has the same layout as Table 4.

The results in Table 5 are supportive of the model. Consistent with Prediction 2 , the coefficients on the measures of $\lambda$ interacted with the IPO indicator variable are negative in all 3 logistic regressions in Panel A and are highly significant in 2 out of 3 specifications, indicating that the likelihood of observing a merger

\section{TABLE 5}

Pre-IPO Valuation Uncertainty and the Likelihood and Timing of Post-IPO Mergers

Panel A of Table 5 presents estimates from logistic regressions of merger likelihood during the 5-year period following an IPO on various measures of valuation uncertainty in the pre-IPO year in a firm's industry. Panel B reports estimates from duration models in which the dependent variable is the time until post-IPO merger, with values censored at 5 years (see Section IV for details). The sample consists of IPOs in years 1981-2002. We match each firm with a control firm using a 2way matching procedure based on size and the market-to-book ratio. Industry valuation uncertainty $(\lambda)$ is estimated using absolute values of valuation errors in a firm's Fama-French (1997) industry in the pre-IPO year. IPO valuation uncertainty is the product of industry valuation uncertainty and IPO indicator variable, equaling 1 for IPO firms and 0 for control firms. Valuation error is defined as i) the revision of the offer price relative to the midpoint of the initial filing range, ii) the residual from the model that predicts the IPO 1st-day return (see Section III for details), or iii) the combination of i) and ii). See Table 4 for definitions of control variables. Here, $p$-values are reported in parentheses. Marginal effects of valuation uncertainty are reported in square brackets in Panel $\mathrm{A}$. Bold represents the main variable of interest.

Panel A. Logit Models

\begin{tabular}{|c|c|}
\hline Variable & $(1)$ \\
\hline Intercept & $\begin{array}{c}-4.871 \\
(0.000)\end{array}$ \\
\hline Valuation error $(\varepsilon)$ & $\begin{array}{c}0.597 \\
(0.000)\end{array}$ \\
\hline IPO valuation uncertainty $(\lambda)$ & $\begin{array}{r}-0.912 \\
(0.014) \\
{[-0.137]}\end{array}$ \\
\hline Industry valuation uncertainty & $\begin{array}{c}0.759 \\
(0.009)\end{array}$ \\
\hline IPO dummy & $\begin{array}{c}0.981 \\
(0.000)\end{array}$ \\
\hline C\&I rate spread & $\begin{array}{c}-0.388 \\
(0.000)\end{array}$ \\
\hline Deregulatory event & $\begin{array}{c}0.201 \\
(0.266)\end{array}$ \\
\hline Abnormal return & $\begin{array}{c}1.848 \\
(0.003)\end{array}$ \\
\hline Noncash working capital & $\begin{array}{r}-0.428 \\
(0.001)\end{array}$ \\
\hline Leverage & $\begin{array}{c}-0.735 \\
(0.000)\end{array}$ \\
\hline $\mathrm{MV} / \mathrm{BV}$ & $\begin{array}{c}0.125 \\
(0.000)\end{array}$ \\
\hline $\mathrm{P} /$ E ratio & $\begin{array}{c}-0.001 \\
(0.360)\end{array}$ \\
\hline $\ln$ (Assets) & $\begin{array}{c}0.342 \\
(0.000)\end{array}$ \\
\hline Excess cash & $\begin{array}{c}0.019 \\
(0.905)\end{array}$ \\
\hline $\begin{array}{l}\text { No. of obs. } \\
R^{2}\end{array}$ & $\begin{array}{l}9,528 \\
0.077\end{array}$ \\
\hline
\end{tabular}

\begin{tabular}{c}
$(2)$ \\
\hline-4.878 \\
$(0.000)$ \\
0.125 \\
$(0.130)$ \\
-0.329 \\
$(0.068)$ \\
{$[-0.049]$} \\
0.121 \\
$(0.382)$ \\
0.849 \\
$(0.000)$ \\
-0.417 \\
$(0.000)$ \\
0.187 \\
$(0.299)$ \\
1.541 \\
$(0.011)$ \\
-0.444 \\
$(0.001)$ \\
-0.858 \\
$(0.000)$ \\
0.134 \\
$(0.000)$ \\
-0.001 \\
$(0.347)$ \\
0.365 \\
$(0.000)$ \\
0.079 \\
$(0.619)$ \\
9,528 \\
0.076 \\
\end{tabular}


TABLE 5 (continued)

Pre-IPO Valuation Uncertainty and the Likelihood and Timing of Post-IPO Mergers

\begin{tabular}{|c|c|c|c|}
\hline Variable & (1) & (2) & (3) \\
\hline Intercept & $\begin{array}{c}8.943 \\
(0.000)\end{array}$ & $\begin{array}{l}8.846 \\
(0.000)\end{array}$ & $\begin{array}{c}8.874 \\
(0.000)\end{array}$ \\
\hline Valuation error $(\varepsilon)$ & $\begin{array}{c}-0.314 \\
(0.020)\end{array}$ & $\begin{array}{l}-0.076 \\
(0.262)\end{array}$ & $\begin{array}{c}-0.105 \\
(0.050)\end{array}$ \\
\hline IPO valuation uncertainty $(\lambda)$ & $\begin{array}{c}0.942 \\
(0.021)\end{array}$ & $\begin{array}{c}0.212 \\
(0.267)\end{array}$ & $\begin{array}{c}0.342 \\
(0.024)\end{array}$ \\
\hline Industry valuation uncertainty & $\begin{array}{c}-0.758 \\
(0.019)\end{array}$ & $\begin{array}{l}-0.191 \\
(0.202)\end{array}$ & $\begin{array}{c}-0.267 \\
(0.020)\end{array}$ \\
\hline IPO dummy & $\begin{array}{c}-0.899 \\
(0.000)\end{array}$ & $\begin{array}{l}-0.701 \\
(0.000)\end{array}$ & $\begin{array}{c}-0.814 \\
(0.000)\end{array}$ \\
\hline C\&I rate spread & $\begin{array}{c}1.152 \\
(0.000)\end{array}$ & $\begin{array}{c}1.159 \\
(0.000)\end{array}$ & $\begin{array}{c}1.154 \\
(0.000)\end{array}$ \\
\hline Deregulatory event & $\begin{array}{c}-0.044 \\
(0.815)\end{array}$ & $\begin{array}{l}-0.035 \\
(0.852)\end{array}$ & $\begin{array}{c}-0.036 \\
(0.849)\end{array}$ \\
\hline Abnormal return & $\begin{array}{l}-0.627 \\
(0.217)\end{array}$ & $\begin{array}{l}-0.572 \\
(0.268)\end{array}$ & $\begin{array}{c}-0.660 \\
(0.198)\end{array}$ \\
\hline Noncash working capital & $\begin{array}{c}0.598 \\
(0.000)\end{array}$ & $\begin{array}{l}0.617 \\
(0.000)\end{array}$ & $\begin{array}{c}0.611 \\
(0.000)\end{array}$ \\
\hline Leverage & $\begin{array}{l}-0.003 \\
(0.990)\end{array}$ & $\begin{array}{l}0.032 \\
(0.870)\end{array}$ & $\begin{array}{c}0.003 \\
(0.987)\end{array}$ \\
\hline MV/BV & $\begin{array}{l}-0.067 \\
(0.000)\end{array}$ & $\begin{array}{l}-0.070 \\
(0.000)\end{array}$ & $\begin{array}{c}-0.066 \\
(0.000)\end{array}$ \\
\hline $\mathrm{P} /$ E ratio & $\begin{array}{c}0.002 \\
(0.012)\end{array}$ & $\begin{array}{c}0.002 \\
(0.016)\end{array}$ & $\begin{array}{c}0.002 \\
(0.017)\end{array}$ \\
\hline In(Assets) & $\begin{array}{l}-0.200 \\
(0.000)\end{array}$ & $\begin{array}{l}-0.208 \\
(0.000)\end{array}$ & $\begin{array}{l}-0.201 \\
(0.000)\end{array}$ \\
\hline Excess cash & $\begin{array}{c}0.087 \\
(0.592)\end{array}$ & $\begin{array}{c}0.051 \\
(0.753)\end{array}$ & $\begin{array}{c}0.066 \\
(0.680)\end{array}$ \\
\hline $\begin{array}{l}\text { No. of obs. } \\
\text { Log likelihood }\end{array}$ & $\begin{array}{l}9,528 \\
-4,103.14\end{array}$ & $\begin{array}{l}9,528 \\
-4,106.96\end{array}$ & $\begin{array}{c}9,528 \\
-4,104.06\end{array}$ \\
\hline
\end{tabular}

within 5 years of IPO is decreasing in pre-IPO valuation uncertainty. The relation between pre-IPO valuation uncertainty and the likelihood of observing post-IPO merger is economically significant. Moving from the 5th to 95th percentiles of valuation uncertainty ( $21 \%$ to $90 \%$ ) reduces the likelihood of observing a merger within 5 years of an IPO by 4.5 percentage points.

The coefficients on the overall industry valuation uncertainty are positive, but they are significant in only 1 out of 3 specifications. This suggests that for nonIPO firms, valuation uncertainty tends to speed up M\&As. However, perhaps due to the potential theoretical ambiguity regarding the relation between investment opportunity uncertainty and the timing of investments, this finding is inconclusive. Consistent with the results in Table 4, the coefficients on measures of valuation surprise are significantly positive ${ }^{21}$ and the signs of the coefficients on the control variables are similar to those in Table 4. In addition, the coefficient on the IPO firm dummy variable is significantly positive. This is consistent with the cash infusion and asymmetric information theories, according to which IPO improves firms' ability to execute acquisitions.

\footnotetext{
${ }^{21}$ Valuation surprises for control firms are assumed to equal 0.
} 
The estimates of duration regressions, reported in Panel B of Table 5, are fully consistent with the logistic regressions in Panel A in the sense that higher pre-IPO valuation uncertainty is associated with significantly larger time spans between IPOs and subsequent mergers for 2 out of 3 measures of valuation uncertainty.

\section{Test of Prediction 3}

Prediction 3 states that the relation between the time it takes an IPO firm to make an acquisition attempt and the cost of going public is expected to be negative and that the likelihood of observing a post-IPO acquisition within a given time frame is increasing in the IPO cost. Table 6 reports the results of estimating equations (29) and (30), augmented by the estimate of firm-specific IPO cost. In order to reduce the influence of share overhang on the empirical results, we normalize the direct cost of IPO by IPO proceeds, as opposed to normalizing them by pre-IPO firm values, as in the calibration.

\section{TABLE 6}

IPO Cost and the Likelihood and Timing of Post-IPO Mergers

\begin{tabular}{|c|c|c|}
\hline Variable & $\begin{array}{l}\text { Panel A. } \\
\text { Logit Model }\end{array}$ & $\begin{array}{c}\text { Panel B. } \\
\text { Duration Model } \\
\end{array}$ \\
\hline Intercept & $\begin{array}{l}-4.306 \\
(0.000)\end{array}$ & $\begin{array}{l}15.099 \\
(0.000)\end{array}$ \\
\hline IPO costs & $\begin{array}{c}6.123 \\
(0.007) \\
{[0.033]}\end{array}$ & $\begin{array}{r}-11.570 \\
(0.009)\end{array}$ \\
\hline Valuation error $(\varepsilon)$ & $\begin{array}{c}0.846 \\
(0.000)\end{array}$ & $\begin{array}{l}-1.466 \\
(0.000)\end{array}$ \\
\hline C\&I rate spread & $\begin{array}{c}0.177 \\
(0.154)\end{array}$ & $\begin{array}{c}0.284 \\
(0.197)\end{array}$ \\
\hline Deregulatory event & $\begin{array}{l}-0.045 \\
(0.863)\end{array}$ & $\begin{array}{c}0.118 \\
(0.809)\end{array}$ \\
\hline Abnormal return & $\begin{array}{c}3.337 \\
(0.000)\end{array}$ & $\begin{array}{l}-5.146 \\
(0.001)\end{array}$ \\
\hline Noncash working capital & $\begin{array}{l}-0.643 \\
(0.000)\end{array}$ & $\begin{array}{c}1.328 \\
(0.000)\end{array}$ \\
\hline Leverage & $\begin{array}{c}-0.613 \\
(0.018)\end{array}$ & $\begin{array}{c}1.316 \\
(0.007)\end{array}$ \\
\hline MV/BV & $\begin{array}{c}0.122 \\
(0.000)\end{array}$ & $\begin{array}{l}-0.234 \\
(0.000)\end{array}$ \\
\hline $\mathrm{P} /$ E ratio & $\begin{array}{c}-0.001 \\
(0.132)\end{array}$ & $\begin{array}{c}0.003 \\
(0.145)\end{array}$ \\
\hline In(Assets) & $\begin{array}{c}0.395 \\
(0.000)\end{array}$ & $\begin{array}{l}-0.837 \\
(0.000)\end{array}$ \\
\hline Excess cash & $\begin{array}{c}0.039 \\
(0.859)\end{array}$ & $\begin{array}{l}-0.223 \\
(0.593)\end{array}$ \\
\hline $\begin{array}{l}\text { No. of obs. } \\
R^{2} \\
\text { Log likelihood }\end{array}$ & $\begin{array}{l}5,142 \\
0.086\end{array}$ & $\begin{array}{l}5,142 \\
-4,003.10\end{array}$ \\
\hline
\end{tabular}


The results in Table 6 provide another piece of evidence in support of the model. First, it follows from Panel A that the cost of going public is positively and significantly related to the likelihood of observing a merger within 5 years of an IPO. Second, as is evident from Panel B, the expected time that elapses between IPO and merger is decreasing in IPO cost.

To summarize the empirical section, the tests of the predictions regarding the timing of post-IPO mergers, reported in Tables 4-6, provide support for our dynamic model of optimal restructuring option exercise in the presence of the option to go public. In particular, the time that is expected to pass between an IPO and merger is decreasing in the valuation surprise revealed at the time of the IPO, is increasing in pre-IPO valuation uncertainty in the firm's industry, and is decreasing in the cost of going public. Also, the likelihood of observing an acquisition within a given time period following an IPO is found to be increasing in the realized valuation surprise, decreasing in pre-IPO valuation uncertainty, and increasing in IPO cost. As discussed previously, this evidence cannot be attributed to alternative models, which do not lead to predictions regarding the timing of post-IPO acquisitions.

\section{Conclusions}

We present a dynamic model of IPOs motivated by the optimal implementation of subsequent takeover strategies. A potential bidder may want to go public in order to learn the true value of its capital stock, which affects the future takeover gain it can realize. Equally importantly, an IPO makes the potential bidder's value observable to the potential target. This allows the 2 firms to exercise their restructuring options optimally. Thus, an IPO removes valuation uncertainty and leads to value-maximizing restructuring policy.

While our analysis focuses on the decision of a potential bidder to go public, it is fully adaptable to the case of a private firm that considers itself a likely acquisition target. Different from the misvaluation-based models of mergers, our model relies on rational investors and efficient markets. Although there is uncertainty regarding a private firm's valuation, there is no asymmetry between the bidder's and target's information. Since the motive for going public in our model is optimization of subsequent acquisition strategy, and since we rule out misvaluation motives for merging and for going public, ours can be considered a "neoclassical" theory of IPOs. Our theory complements the asymmetric-information-based and cash-infusion-based theories of M\&As following IPOs. For example, our model is useful for explaining post-IPO cash acquisitions by firms that issue relatively little new equity during their IPOs.

In addition to illustrating a new motivation for going public, our model complements existing theories linking IPOs and M\&As by generating a number of unique empirical predictions that relate the likelihood and timing of mergers following IPOs to the degree of valuation uncertainty private firms face, the valuation surprises realized at the time of IPO, and the cost of going public. Calibration of the model using 27 years of data on IPOs and M\&As shows that the effects of valuation uncertainty and valuation surprises on the likelihood and timing of post-IPO mergers are economically large. 
We perform empirical tests of the model's predictions regarding the determinants of the likelihood of going public prior to attempting a merger and regarding the timing of post-IPO merger attempts. Consistent with the model, the likelihood of observing a post-IPO merger is increasing in the valuation surprise realized at the time of IPO, and the time between IPO and subsequent merger is decreasing in the valuation surprise. Also, consistent with the model, the time between an IPO and a subsequent merger is increasing in the degree of pre-IPO valuation uncertainty and is decreasing in the cost of going public, while the likelihood of observing a merger within 5 years of an IPO is decreasing in the degree of valuation uncertainty and is increasing in the IPO cost.

\section{Appendix. Proofs and Derivations}

\section{Optimal Restructuring Threshold}

In what follows, we outline the solution of the model for the case of a public bidder. The solution for the private bidder case is obtained along the same lines. In the region in which it is not optimal to make a takeover bid immediately, the instantaneous change in the value of a public bidder's option to merge, $O_{\mathrm{PUB}}^{B}$, satisfies (by an application of Itô's lemma)

$$
\begin{aligned}
d O_{\mathrm{PUB}}^{B}= & d X O_{\mathrm{PUB}_{X}}^{B}+d Y O_{\mathrm{PUB}_{Y}}^{B} \\
& +\left[\frac{1}{2} \sigma_{X}^{2} X^{2} O_{\mathrm{PUB}_{X X}}^{B}+\rho \sigma_{X} \sigma_{Y} X Y O_{\mathrm{PUB}_{X Y}}^{B}+\frac{1}{2} \sigma_{Y}^{2} Y^{2} O_{\mathrm{PUB}_{Y Y}}^{B}\right] d t .
\end{aligned}
$$

The equilibrium expected return on the restructuring option is $r$. Combining this equilibrium condition with equation (A-1) and taking expectations of both sides results in the following partial differential equation:

$$
\begin{aligned}
r O_{\mathrm{PUB}}^{B}= & \mu_{X} X O_{\mathrm{PUB}_{X}}^{B}+\mu_{Y} Y O_{\mathrm{PUB}_{Y}}^{B}+\frac{1}{2} \sigma_{X}^{2} X^{2} O_{\mathrm{PUB}_{X X}}^{B} \\
& +\rho \sigma_{X} \sigma_{Y} X Y O_{\mathrm{PUB}_{X Y}}^{B}+\frac{1}{2} \sigma_{Y}^{2} Y^{2} O_{\mathrm{PUB}_{Y Y}}^{B},
\end{aligned}
$$

Similar to expression (6), since the value function $O_{\mathrm{PUB}}^{B}$ is linearly homogeneous in $X$ and $Y$, the optimal restructuring policy can be described using the ratio $R=X / Y$, and the value of the restructuring option can be written as

$$
O_{\mathrm{PUB}}^{B}(X, Y)=Y O_{\mathrm{PUB}}^{B}(X / Y, 1)=Y O_{\mathrm{PUB}}^{B}(R) .
$$

Successive differentiation yields

$$
\begin{aligned}
O_{\mathrm{PUB}_{X}}^{B}(X, Y) & =O_{\mathrm{PUB}_{R}}^{B}(R), \\
O_{\mathrm{PUB}_{Y}}^{B}(X, Y) & =O_{\mathrm{PUB}^{B}}^{B}(R)-R O_{\mathrm{PUB}_{R}}^{B}(R), \\
O_{\mathrm{PUB}_{X X}}^{B}(X, Y) & =O_{\mathrm{PUB}_{R}}^{B}(R) / Y, \\
O_{\mathrm{PUB}_{X Y}}^{B}(X, Y) & =-R O_{\mathrm{PUB}_{R R}}^{B}(R) / Y, \\
O_{\mathrm{PUB}_{Y Y}}^{B}(X, Y) & =R^{2} O_{\mathrm{PUB}_{R R}}^{B}(R) / Y .
\end{aligned}
$$

Substituting expressions (A-3)-(A-8) into the partial differential equation (A-2) yields the ordinary differential equation

$$
\begin{aligned}
& \frac{1}{2}\left[\sigma_{X}^{2}-2 \rho \sigma_{X} \sigma_{Y}+\sigma_{Y}^{2}\right] R^{2} O_{\mathrm{PUB}_{R R}}^{B}(R)+\left[\mu_{X}-\mu_{Y}\right] R O_{\mathrm{PUB}_{R}}^{B}(R)= \\
& \quad\left[r-\mu_{Y}\right] O_{\mathrm{PUB}}^{B}(R),
\end{aligned}
$$


with the value-matching and smooth-pasting conditions

$$
\begin{aligned}
O_{\mathrm{PUB}}^{B}\left(R_{B_{\mathrm{PUB}}}^{*}\right) & =\xi \alpha K_{T}\left[R_{B_{\mathrm{PUB}}}^{*}(1+\varepsilon)-1\right]-c K_{B} R_{B_{\mathrm{PUB}}}^{*}[1+\varepsilon], \\
O_{\mathrm{PUB}} & \left(R_{B_{\mathrm{PUB}}}^{*}\right)=\xi \alpha K_{T}[1+\varepsilon]-c K_{B}[1+\varepsilon],
\end{aligned}
$$

as well as the no-bubbles condition

$$
\lim _{R \rightarrow 0} O_{\mathrm{PUB}}^{B}(R)=0 .
$$

The general solution to equation (A-9) is given by

$$
O_{\mathrm{PUB}}^{B}(R)=A R^{\beta_{1}}+B R^{\beta_{2}},
$$

where $A$ and $B$ are positive constants, and $\beta_{1}$ and $\beta_{2}$ are the positive and negative roots of the quadratic equation

$$
\frac{1}{2}\left[\sigma_{X}^{2}-2 \rho \sigma_{X} \sigma_{Y}+\sigma_{Y}^{2}\right] \beta[\beta-1]+\left[\mu_{X}-\mu_{Y}\right] \beta-r+\mu_{Y}=0 .
$$

Condition (A-12) implies that $B=0$. Thus, denoting $\beta_{1}$ as $\beta$, conditions (A-10) and (A-11) can be rewritten as

$$
A\left[R_{B_{\mathrm{PUB}}}^{*}\right]^{\beta}=\xi \alpha K_{T}\left[R_{B_{\mathrm{PUB}}}^{*}(1+\varepsilon)-1\right]-c K_{B} R_{B_{\mathrm{PUB}}}^{*}[1+\varepsilon],
$$

and

$$
\beta A\left[R_{B_{\mathrm{PUB}}}^{*}\right]^{\beta-1}=\xi \alpha K_{T}[1+\varepsilon]-c K_{B}[1+\varepsilon] .
$$

Solving the system of equations (A-15) and (A-16) yields

$$
A=\left[R_{B_{\mathrm{PUB}}}^{*}\right]^{-\beta}\left[\xi \alpha K_{T}\left(R_{B_{\mathrm{PUB}}}^{*}\{1+\varepsilon\}-1\right)-c K_{B} R_{B_{\mathrm{PUB}}}^{*}(1+\varepsilon)\right],
$$

and

$$
R_{B_{\mathrm{PUB}}}^{*}=\frac{\beta}{\beta-1} \frac{\xi \alpha K_{T}}{\left(\xi \alpha K_{T}-c K_{B}\right)(1+\varepsilon)} .
$$

The value of the target's restructuring option, $R_{T_{\mathrm{PUB}}}^{*}$, is obtained along the same lines.

\section{Equilibrium Value of the Restructuring Option}

Again, we describe the solution for the case of a public bidder; the private bidder case is solved analogously. Plugging $\xi^{*}$ and $R_{B \mathrm{PUB}}^{*}$ in expressions (13) and (14), respectively, into expressions (A-17) and (A-13) yields the value of the public bidder's restructuring option for the region $R_{0}<R_{\mathrm{PUB}}^{*}$ :

$$
O_{\mathrm{PUB}}^{B}\left(R_{0}, \varepsilon\right)=\frac{1}{\beta-1}\left[\frac{R_{0}(1+\varepsilon)(\beta-1)}{\beta} \frac{\alpha K_{T}-c K_{B}}{(\alpha+c) K_{T}}\right]^{\beta} \frac{[\alpha+c] K_{B} K_{T}}{K_{B}+K_{T}} .
$$

If $R_{0} \geq R_{\mathrm{PUB}}^{*}$, then the bidder launches a takeover bid immediately (at $R_{0}$ ). Plugging $\xi^{*}$ in expression (13) into expression (A-15) yields the value of the takeover gain accruing to the bidder:

$$
O_{\mathrm{PUB}}^{B}\left(R_{0}, \varepsilon\right)=\left[R_{0}(1+\varepsilon)\left(\alpha K_{T}-c K_{B}\right)-(\alpha+c) K_{T}\right] \frac{K_{B}}{K_{B}+K_{T}} .
$$




\section{IPO and the Value of the Restructuring Option}

Integrating the expressions in equation (25) in region 2 yields the following result:

$$
\begin{aligned}
O_{\mathrm{IPO}}^{B}\left(R_{0}\right)= & \sup _{R^{\mathrm{IPO}}}\left(\frac{R_{0}}{R^{\mathrm{IPO}}}\right)^{\beta} \\
& \left\{\frac{1}{\beta-1}\left(\frac{R^{\mathrm{IPO}}(\beta-1)}{\beta} \frac{\alpha K_{T}-c K_{B}}{(\alpha+c) K_{T}}\right)^{\beta} \frac{[\alpha+c] K_{B} K_{T}}{K_{B}+K_{T}}\right. \\
\times & \left\{\frac{\left(1+\varepsilon^{*}\right)^{\beta+1}-(1-\lambda)^{\beta+1}}{2 \lambda(\beta+1)}\right\} \\
+ & \frac{K_{B}\left(\lambda-\varepsilon^{*}\right)}{2 \lambda\left(K_{B}+K_{T}\right)}\left\{\frac{1}{2} R^{\mathrm{IPO}}\left(\lambda+\varepsilon^{*}+2\right)\left(\alpha K_{T}-c K_{B}\right)-(\alpha+c) K_{T}\right\} \\
- & \left.\eta K_{B} R^{\mathrm{IPO}}\right\} .
\end{aligned}
$$

\section{References}

Abel, A. B. "Optimal Investment Under Uncertainty." American Economic Review, 73 (1983), $228-233$.

Alt1, A. "IPO Market Timing." Review of Financial Studies, 18 (2005), 1105-1138.

Amihud, Y., and H. Mendelson. "Liquidity and Asset Prices: Financial Management Implications." Financial Management, 17 (1988), 5-15.

Andrade, G., and E. Stafford. "Investigating the Economic Role of Mergers." Journal of Corporate Finance, 10 (2004), 1-36.

Beatty, R. P., and J. R. Ritter. "Investment Banking, Reputation, and the Underpricing of Initial Public Offerings." Journal of Financial Economics, 15 (1986), 213-232.

Benninga, S.; M. Helmantel; and O. Sarig. "The Timing of Initial Public Offerings." Journal of Financial Economics, 75 (2005), 115-132.

Benveniste, L. M.; W. Y. Busaba; and W. J. Wilhelm Jr. "Information Externalities and the Role of Underwriters in Primary Equity Markets." Journal of Financial Intermediation, 11 (2002), 61-86.

Benveniste, L. M., and P. A. Spindt. "How Investment Bankers Determine the Offer Price and Allocation of New Issues." Journal of Financial Economics, 24 (1989), 343-361.

Bernile, G.; E. Lyandres; and A. Zhdanov. "A Theory of Strategic Mergers." Review of Finance, forthcoming (2011).

Boudoukh, J.; R. Michaely; M. Richardson; and M. R. Roberts. "On the Importance of Measuring Payout Yield: Implications for Empirical Asset Pricing.” Journal of Finance, 62 (2007), 877-915.

Bradley, D. J., and B. D. Jordan. "Partial Adjustment to Public Information and IPO Underpricing." Journal of Financial and Quantitative Analysis, 37 (2002), 595-616.

Brau, J. C., and S. E. Fawcett. "Initial Public Offerings: An Analysis of Theory and Practice." Journal of Finance, 61 (2006), 399-436.

Brau, J. C.; B. Francis; and N. Kohers. "The Choice of IPO versus Takeover: Empirical Evidence." Journal of Business, 76 (2003), 583-612.

Celikyurt, U.; M. Sevilir; and A. Shivdasani. "Going Public to Acquire: The Acquisition Motive in IPOs.” Journal of Financial Economics, 96 (2010), 345-363.

Chemmanur, T. J., and P. Fulghieri. "A Theory of the Going-Public Decision." Review of Financial Studies, 12 (1999), 249-279.

Chen, H.-C., and J. R. Ritter. "The Seven Percent Solution.” Journal of Finance, 55 (2000), 11051131.

Derrien, F., and A. Kecskés. "The Initial Public Offerings of Listed Firms.” Journal of Finance, 62 (2007), 447-479.

Dow, J., and G. Gorton. "Stock Market Efficiency and Economic Efficiency: Is There a Connection?" Journal of Finance, 52 (1997), 1087-1129.

Eckbo, B. E.; R. M. Giammarino; and R. L. Heinkel. "Asymmetric Information and the Medium of Exchange in Takeovers: Theory and Tests." Review of Financial Studies, 3 (1990), 651-675.

Fama, E. F., and K. R. French. "Industry Costs of Equity." Journal of Financial Economics, 43 (1997), $153-193$. 
Fishman, M. J. "Preemptive Bidding and the Role of the Medium of Exchange in Acquisitions." Journal of Finance, 44 (1989), 41-57.

Hackbarth, D., and J. Miao. "The Dynamics of Mergers and Acquisitions in Oligopolistic Industries." Working Paper, University of Illinois and Boston University (2007).

Hackbarth, D., and E. Morellec. "Stock Returns in Mergers and Acquisitions." Journal of Finance, 63 (2008), 1213-1252.

Hanley, K. W. "The Underpricing of Initial Public Offerings and the Partial Adjustment Phenomenon.' Journal of Financial Economics, 34 (1993), 231-250.

Hansen, R. G. "A Theory for the Choice of Exchange Medium in the Market for Corporate Control." Journal of Business, 60 (1987), 75-95.

Harford, J. "What Drives Merger Waves.” Journal of Financial Economics, 77 (2005), 529-560.

Holmström, B., and J. Tirole. "Market Liquidity and Performance Monitoring." Journal of Political Economy, 101 (1993), 678-709.

Hovakimian, A., and I. Hutton. "Merger-Motivated IPOs." Financial Management, 39 (2010), 15471573.

Jovanovic, B., and P. L. Rousseau. "The Q-Theory of Mergers.” American Economic Review, 92 (2002), 198-204.

Kecskés, A. "Initial Public Offerings: The Origin of Investor Recognition?" Working Paper, Virginia Tech (2008).

Lambrecht, B. M. "The Timing and Terms of Mergers Motivated by Economies of Scale." Journal of Financial Economics, 72 (2004), 41-62.

Lambrecht, B. M., and S. C. Myers. "A Theory of Takeovers and Disinvestment.” Journal of Finance, 62 (2007), 809-845.

Leahy, J. V., and T. M. Whited. "The Effect of Uncertainty on Investment: Some Stylized Facts." Journal of Money, Credit, and Banking, 28 (1996), 64-83.

Leland, H. E. "Financial Synergies and the Optimal Scope of the Firm: Implications for Mergers, Spinoffs, and Structured Finance.” Journal of Finance, 62 (2007), 765-807.

Ljungqvist, A., and W. J. Wilhelm Jr. "IPO Pricing and the Dot-Com Bubble." Journal of Finance, 58 (2003), 723-752.

Loughran, T., and J. R. Ritter. "Uniformly Least Powerful Tests of Market Efficiency." Journal of Financial Economics, 55 (2000), 361-389.

Loughran, T., and J. Ritter. "Why Has IPO Underpricing Changed over Time." Financial Management, 33 (2004), 5-37.

Lowry, M.; M. S. Officer; and G. W. Schwert. "The Variability of IPO Initial Returns." Journal of Finance, 65 (2010), 425-465.

Luo, Y. "Do Insiders Learn from Outsiders? Evidence from Mergers and Acquisitions." Journal of Finance, 60 (2005), 1951-1982.

Maksimovic, V., and G. Phillips. "The Market for Corporate Assets: Who Engages in Mergers and Asset Sales and Are There Efficiency Gains.” Journal of Finance, 56 (2001), 2019-2065.

Maksimovic, V., and G. Phillips. "Do Conglomerate Firms Allocate Resources Inefficiently across Industries? Theory and Evidence." Journal of Finance, 57 (2002), 721-767.

Maksimovic, V.; G. Phillips; and L. Yang. "Public and Private Merger Waves." Working Paper, University of Maryland (2010).

Maksimovic, V., and P. Pichler. "Technological Innovation and Initial Public Offerings." Review of Financial Studies, 14 (2001), 459-494.

Margsiri, W.; A. S. Mello; and M. E. Ruckes. "A Dynamic Analysis of Growth via Acquisitions." Review of Finance, 12 (2008), 635-671.

McDonald, R., and D. Siegel. "The Value of Waiting to Invest.” Quarterly Journal of Economics, 101 (1986), 707-727.

Mello, A. S., and J. E. Parsons. "Going Public and the Ownership Structure of the Firm." Journal of Financial Economics, 49 (1998), 79-109.

Mikkelson, W. H.; M. M. Partch; and K. Shah. "Ownership and Operating Performance of Companies That Go Public.“ Journal of Financial Economics, 44 (1997), 281-307.

Mitchell, M. L., and J. H. Mulherin. "The Impact of Industry Shocks on Takeover and Restructuring Activity.” Journal of Financial Economics, 41 (1996), 193-229.

Morellec, E., and A. Zhdanov. "The Dynamics of Mergers and Acquisitions." Journal of Financial Economics, 77 (2005), 649-672.

Morellec, E., and A. Zhdanov. "Financing and Takeovers.” Journal of Financial Economics, 87 (2008), $556-581$.

Pindyck, R. S. "Irreversible Investment, Capacity Choice, and the Value of the Firm." American Economic Review, 78 (1988), 969-985. 
Rau, P. R., and A. Stouraitis. "Patterns in the Timing of Corporate Event Waves." Journal of Financial and Quantitative Analysis, 46 (2011), 209-246.

Ritter, J. R., and I. Welch. "A Review of IPO Activity, Pricing and Allocations." Journal of Finance, 57 (2002), 1795-1828.

Roberts, K., and M. L. Weitzman. "Funding Criteria for Research, Development, and Exploration Projects." Econometrica, 49 (1981), 1261-1288.

Schultz, P., and M. Zaman. "Do the Individuals Closest to Internet Firms Believe They Are Overvalued?" Journal of Financial Economics, 59 (2001), 347-381.

Stiglitz, J. E., and A. Weiss. "Credit Rationing in Markets with Imperfect Information." American Economic Review, 71 (1981), 393-410.

Stoughton, N. M.; K. P. Wong; and J. Zechner. "IPOs and Product Quality." Journal of Business, 74 (2001), 375-408.

Strebulaev, I. A. "Do Tests of Capital Structure Mean What They Say?” Journal of Finance, 62 (2007), $1747-1787$.

Subrahmanyam, A., and S. Titman. "Feedback from Stock Prices to Cash Flows." Journal of Finance, 56 (2001), 2389-2413.

Zingales, L. "Inside Ownership and the Decision to Go Public." Review of Economic Studies, 62 (1995), 425-448. 